\title{
LA DOCUMENTACIÓN SOBRE LAS MEMORIAS DEL VIAJE DEL MARQUÉS DE VALDEFLORES POR ESPAÑA (REAL ACADEMIA DE LA HISTORIA, MS. 9/7018)*
}

\author{
DOCUMENTS OF THE MARQUIS OF VALDEFLORES JOURNEY OVER \\ SPAIN (REAL ACADEMIA DE LA HISTORIA, MS. 917018)
}

\author{
por \\ ROSARIO CEBRIÁN FERNÁNDEZ \\ VIRGINIA SALAMANQUÉS PÉREZ \\ ESTHER SÁNCHEZ MEDINA
}

RESUMEN

\begin{abstract}
In 1752, the marquess of Valdeflores began a journey over Spain, commissioned by the Real Academia de la Historia to write a National History. For two years he went over Extremadura and part of Andalucía with a draughtsman, carrying out a complete description of ancient inscriptions and monuments. The $1^{\text {st }}$ volume of this journey's Memorias is preserved in the bundle 9/7018 of the Academia's library, arranged for a future publication, never carried out.
\end{abstract}

En 1752, el Marqués de Valdeflores inició un viaje por la geografía española, comisionado por la Real Academia de la Historia, para formar una historia de España. Durante dos años recorrió Extremadura y parte de Andalucía, acompañado de un dibujante, realizando una completa descripción de inscripciones y monumentos antiguos. El volumen I de las Memorias de su viaje se conserva en el legajo 9/7018 de la biblioteca de la Academia, ordenadas para una futura publicación, que nunca llegó a producirse.

Palabras claves Valdeflores, Antigüedades, Inscripciones, Extremadura, Andalucía.

Key words Valdeflores, Antiquities, Inscriptions, Extremadura, Andalucía.

El 21 de noviembre de 1760, Luis José Velázquez de Velasco, Marqués de Valdeflores (1722-1772), leyó en la Real Academia de la Historia una memoria en la que daba cuenta del viaje literario que había emprendido ocho años antes, con el fin de recoger los documentos necesarios para formar la historia

* Este artículo se realiza dentro del proyecto CAM 06/0098/2003. 
antigua de España (ms. 9/4160/1). Su viaje fue, sin duda, una de las empresas histórico-arqueológicas más importantes del siglo XVIII, ya que, por primera vez, se viajaba acompañado de un dibujante para copiar directamente los monumentos y evitar, de esta manera, las falsificaciones ${ }^{1}$.

Unos años antes, en 1747, y bajo el auspicio del rey Fernando VI, Velázquez se había propuesto hacer una Colección general de todos los antiguos Monumentos originales y contemporáneos de la Historia de España; y después formar una Historia general de la Nación únicamente deducida de ellos, idea emprendida a partir de 1750 con el estudio del Archivo de la Santa Iglesia de Toledo por el jesuita Andrés Marcos Burriel, durante cinco años y por Francisco Pérez Bayer hasta 1752, año en el que pasó a ser canónigo de Barcelona. Otras personas fueron también comisionadas para reconocer el resto de los archivos eclesiásticos de España, cuyos nombres se mencionan en la noticia que publicó de su viaje (Velázquez 1765).

La biblioteca de la Real Academia de la Historia conserva un legajo escrito por Velázquez (ms. 9/7018) con el título Memorias de el Viage de España que de orden del Rey empezó à executar D. Luis Joseph Velázquez, Señor de Valdeflores y Sierrablanca, Caballero de la Orden de Santiago. Tomo I, en el que ordena una gran parte de las anotaciones que hizo de su viaje e incluye índices finales y notas a pie de página para su publicación. El volumen presenta una segunda copia con diferente letra, a la que le falta la Parte I que el autor dedicó a la explicación y los motivos de su viaje. Desconocemos la fecha concreta en la que Velázquez lo escribió, pero las referencias en el texto a algunas de sus obras publicadas en el año de 1759 (Velázquez 1759) y la afirmación de que sus memorias son el fruto de un trabajo de 12 años (ms. 9/7018, 23[4])2, fechan el documento en un momento posterior a 1764 (fig. 1).

\section{EL VIAJE DEL MARQUÉS DE VALDEFLORES}

El día 2 de noviembre de 1752, el Marqués de la Ensenada -protector de Velázquez hasta el momento de su caída en desgracia como ministro- firmó la Instrucción y Órdenes para llevar a cabo el viaje. En ella, se detallaba el itinerario que debía seguir Velázquez, aunque no pudo completar el reconocimiento de todos los monumentos de la Antigüedad por falta de recursos económicos suficientes (Álvarez 1996: 34). Durante el viaje debía examinar, copiar y recoger todos los antiguos monumentos que pudieran servir para formar la Historia Antigua de España y, posteriormente, elaborar una relación detallada del trabajo realizado (CAG/9/7980/5(42) en Maier 2002: 12-16):

$1^{\circ}$ viajar todas las Provincias de España, empezando por Extremadura de León, y continuando por las cuatro de Andaluzia, y por las de Murcia, y Valencia; por Cataluña, Aragon, Navarra, Guipúzcoa, Vizcaya, Alaba, quatro villas de a la Mar, Asturias, Galicia, León y las dos Castillas.

$2^{\circ}$ hazer en todas ellas las observaciones necesarias para el conocimiento de la antigua Geografía del pais.

$3^{\circ}$ examinar, copiar y recoger de los Archivos, Bibliotecas, Gabinetes y demas parages publicos, o privados, todos los antiguos monumentos de la Nación Española, que pudiesen ser de algun uso para su Historia.

$4^{\circ}$ formar unas exactas Memorias de mi viaje con la noticia de todo lo executado en el.

El Marqués de Valdeflores salió de Madrid el día 1 de diciembre de 1752, acompañado de un dibujante, Esteban Rodríguez - que murió dos años más tarde en Madrid-, atravesando la provincia de Toledo y entrando en Extremadura por Cáceres. Durante el viaje recibió un sueldo de tres mil reales

1. Sobre la colección de Velázquez conservada en la biblioteca de la Academia véase Abascal-Cebrián 2005: 465-490.

2. Al tratarse de un manuscrito en cuarto, a partir de ahora, los folios se citarán de la siguiente forma: la primera cifra corresponde al número de folio, y entre corchetes el número de cuarto correspondiente. 


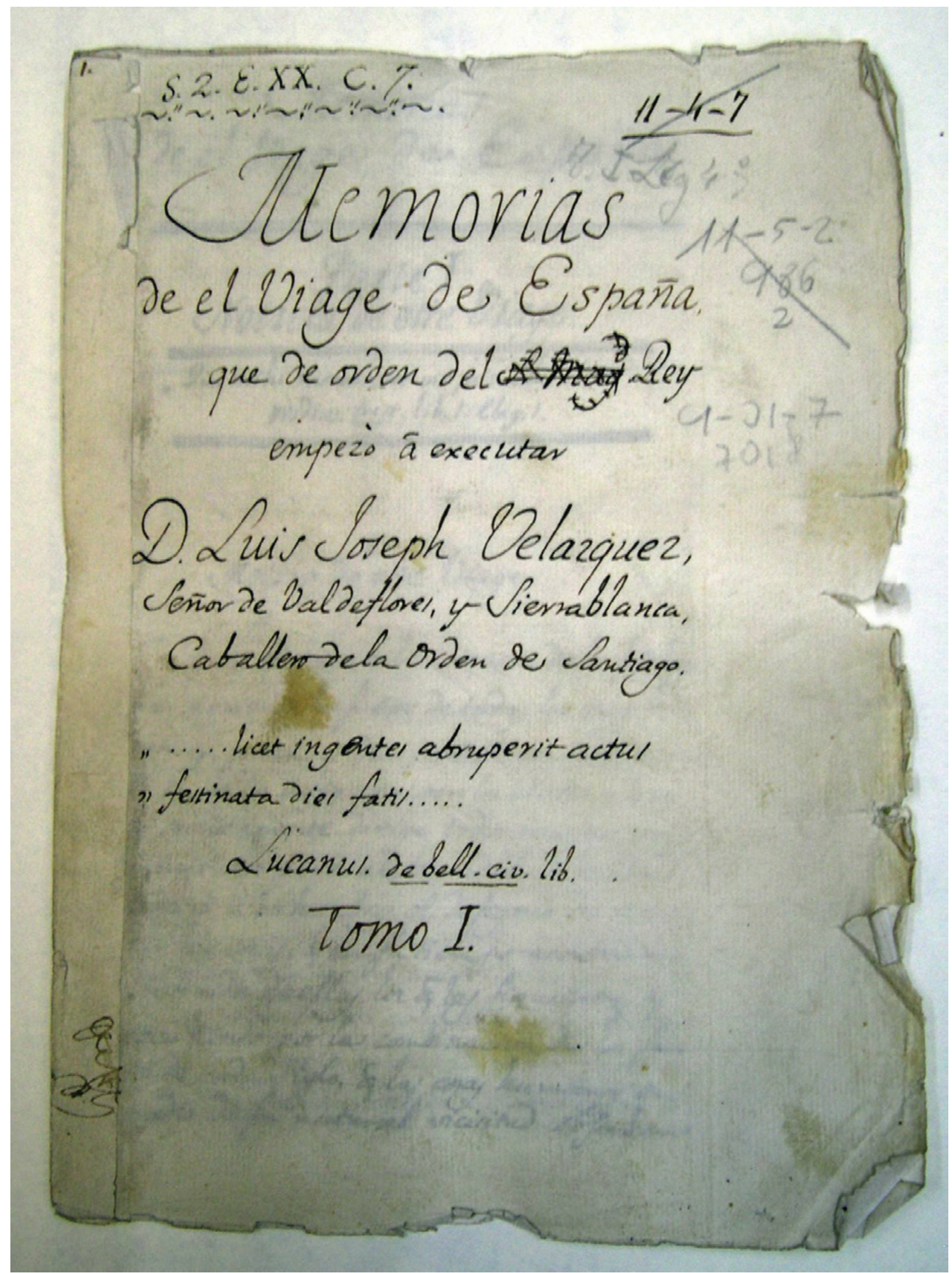

Fig. 1. Portada de las Memorias escrita por Luis José de Velázquez. RAH ms. 9/7018.

ISSN: 1133-4525 ISSN-e: 2255-3924 
mensuales con la obligación de llevar consigo un Dibujante, y se le concedió la facultad de hacer algunas pequeñas escabaciones siempre q(u)e lo hallase por conveniente, y de comprar Medallas, y otros Monumentos de la antiguedad que no fuesen de mucho coste pues en este caso se le prevenia diese cuenta, y esperase las or(de)n(e)s que sobre este particular se le comunicasen (mss. 9/4160 y 11/8055/32). En la primera etapa de su viaje visitó una parte del Reino de Castilla la nueva, toda la Provincia de Estremadura de Leon, y parte del Reino de Leon hasta Salamanca. El día 7 de septiembre de 1753 sale de Extremadura en dirección al Reino de Sevilla, permaneciendo en Andalucía hasta el último día de 1754, fecha en la que se le suspende la pensión que se le había otorgado para realizar el viaje.

Velázquez argumenta que a partir de este momento en vista de que el Rey no havia revocado el Decreto, en que me ordenó executar este viaje, no por el presente se me ordenaba suspenderlo, y solo se mandaba suspender la pensión que para sus gastos se me havia consignado, me resolbi a continuarle a mi costa, en la manera, $i$ hasta tanto que me fuese posible (mss. 9/4160/1, fol. 6-7 y 9/7018, $3[2-3])$. Al contrario de esta afirmación, en la colección de Valdeflores, que se conserva en la biblioteca de la Academia, no encontramos evidencias de que siguiese viajando por el resto de las provincias españolas. Los documentos referentes a los dos primeros años de su viaje se corresponden con notas originales del autor que demuestran la presencia in situ de los lugares descritos, mientras que para el resto de provincias, que él afirma haber recorrido a sus expensas, no poseemos una información tan detallada, sino que se trata de descripciones y copias de textos sacados de obras, tanto manuscritas como impresas, de otros autores.

Velázquez debía informar puntualmente de las averiguaciones hechas en punto de Geografia antigua, y de todo lo más que fuese relativo a su comisión. En total, remitió nueve cartas a Agustín de Montiano y Luyando, director de la Real Academia de la Historia, desde el 6 de enero de 1753 hasta el 29 de julio de 1754. Desde Granada le escribe el día 2 de octubre de 1753, detallándole el itinerario que había seguido en su viaje por Extremadura (CAG/9/7980/5, fol. 42). Más tarde, envió una Noticia con fecha 21 de noviembre de 1760, en la que expresaba $1^{\circ}$ los motivos que havia tenido el Rey para mandarle hacer el viaje $2^{\circ}$ de la manera que lo habia ejecutado, $3^{\circ}$ del estado en que tenía las obras que el Rey le habia mandado hacer. Al mismo tiempo, comunicaba que su trabajo se componía de cinco colecciones, que ocupaban 57 volúmenes en folio (ms 9/7160/1, fol. 20).

De las Memorias de su viaje sólo se publicó una breve Noticia en 1765, en la que hacia referencia al número de documentos recogidos para el estudio de la historia antigua de España, que ascendía a un total de 13.664. De ellos, 7.008 son diplomas, 4.134 inscripciones, 2.021 medallas, 439 escritores históricos originales y contemporáneos y 62 monumentos de pintura, escultura y arquitectura (Velázquez 1765: 34-35). El legajo 9/7018 es el único manuscrito con autoría de Velázquez que parece tratarse de una copia a limpio de sus observaciones durante el viaje. Además, en su portada se lee Tomo I, lo que parece indicar que pretendía ser el primer volumen de sus Memorias. Por otro lado, conocemos un índice de las láminas (mss. 9/4118/9-10) que acompañarían al texto de un tomo $1^{\circ}$ que, presumiblemente, corresponde al contenido de este manuscrito (fig. 2).

La obra que elaboró a lo largo de su viaje, parte de la cual se encontraba en la casa familiar de Málaga, despertó, en 1795, el interés de la Real Academia de la Historia, para realizar a partir de la misma la Descripción General de la España antigua y moderna (ms. 9/4161). La colección de Velázquez llegó a la Academia a finales de 1796 o principios de 1797, tras casi dos años de gestiones con su hermano Francisco (ms. 9/4160). El Duque de la Alcudia solicitó en agosto de 1795 al entonces Marqués de Valdeflores la remisión de todas las obras que dexó ineditas su hermano D. Luis de Velazquez por haberlas trabajado expresamente de orden del Sr Rey D. Fernando VI, y a expensas de la real hacienda. El 3 de septiembre de ese mismo año, Francisco Velázquez de Velasco escribió a Tomás Antonio Sánchez, director de la Academia, comunicándole que estaba preparando la lista de los 


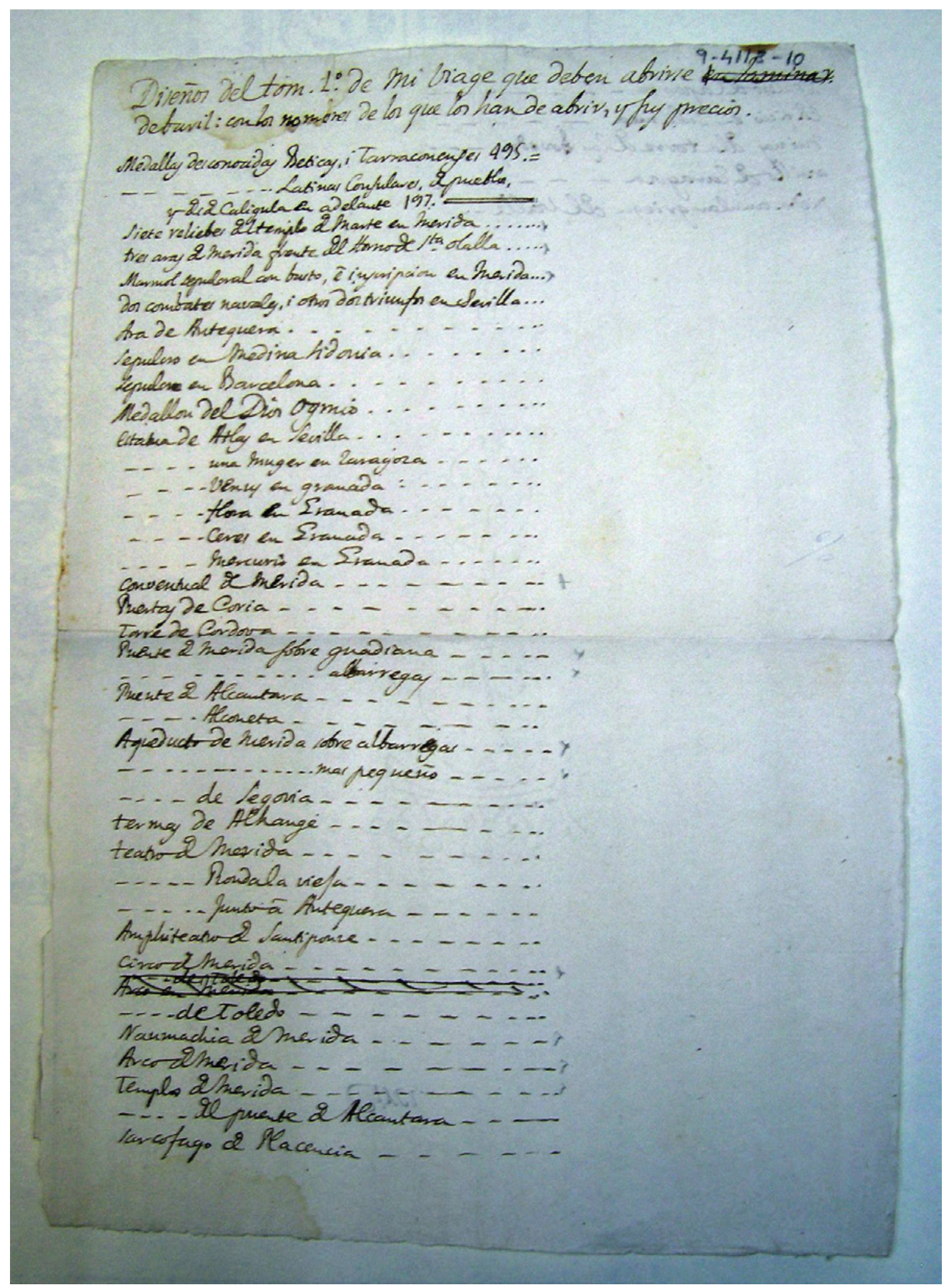

Fig. 2. Índice de las ilustraciones que Velázquez elabora para la publicación del Tomo I de su viage. RAH ms. 9/4118/10. 
manuscritos que dejó su hermano y que aceptaba el ofrecimiento de remitirlos para que la Academia realizase una copia y le fuesen devueltos los originales. En esa misma carta desvelaba que el título de Marqués de Valdeflores, que a la muerte de Luis José había pasado a su hermano Carlos, se ha perdido por no haverse pagado a S. M. por mis Hermanos lanzas, ni medias annatas. El 30 de abril de 1796, Francisco Velázquez remite dos cartas, una dirigida al duque de la Roca y otra al director de la Academia, con aviso de remisión de cuatro cajones con los manuscritos de su difunto hermano. El 23 de diciembre de 1796, Manuel Godoy comunica al Secretario de la Academia que la Secretaría de Estado procederá a enviar la colección Velázquez a esta institución de la mano de Francisco García Portero. La lista de los libros que se remitieron desde Málaga al Príncipe de la Paz contenía un total de 102 legajos (Abascal-Cebrián 2005: 490).

\title{
2. EL VIAJE Y LA METODOLOGÍA
}

Para llevar a cabo este trabajo, Velázquez dividió los documentos históricos recogidos en distintas categorías o clases, incluidas en los diferentes artículos en que, según él, debía subdividirse la Historia General de España:

\author{
Artículo 1 $1^{\circ}$ : Colección de los Escritores originales de las cosas de España \\ Artículo $2^{\circ}$ : Colección de los Diplomas \\ Artículo $3^{\circ}$ : Colección de las Inscripciones \\ Artículo $4^{\circ}$ : Colección de las Medallas \\ Artículo 5 ${ }^{\circ}$ : Colección de los Monumentos de Pintura, Escultura, y Arquitectura; y de los Instrumentos, mue- \\ bles, y demás utensilios de la vida civil \\ Articulo $6^{\circ}$ : Colección de los antiguos Escritores Españoles sobre cada uno de los diferentes ramos de los \\ conocimientos humanos.
}

El principal objetivo era determinar la verdadera situación de los pueblos antiguos relativamente a la de los Modernos (ms 9/7018, 4 [3]). Para ello, el análisis detallado de los distintos autores que habían tratado sobre la Península se volvía imprescindible, así como conocer de forma exhaustiva la topografía antigua, a través de los restos arqueológicos, monedas, inscripciones, diplomas y estudios etimológicos.

Entre las distintas innovaciones historiográficas debemos destacar que Velázquez no concibe ya la historia como res gestae, sino como historiae rerum gestarum, así puede deducirse de sus palabras cuando afirma: la antigua Historia general de qualquiera Nación, contemplada por orden a un Escritor, que en los tiempos mui posteriores a ella intente escribirla, no es, para decirlo assi la narración de las cosas que sucedieron, sino de las cosas, que los Escritores, y monumentos originales, y contemporáneos aseguran que han sucedido (ms. 9/7018, 6[1]). Una vez asumida la limitación que implica la distancia entre el objeto histórico y el trabajo historiográfico, Velázquez lleva a cabo una estructuración de su obra, atendiendo a una metodología notablemente más científica y avanzada que la utilizada por muchos de sus contemporáneos. La Historia general de España quedaría subdividida de la siguiente manera: Monumentos históricos, Memorias históricas y la Historia assi dicha con propiedad:

La Historia cuio conocimiento puede ser util, no es la prolixa narración de todos los acontecimientos, sino de aquellos, que pueden instruir; y por consiguiente que son dignos de la memoria. No todos los sucesos instruyen, ni merecen pasar a la posteridad: asi no todos los hechos examinados por las MEMORIAS HISTÓRICAS tienen lugar en la HisTORIA ASí DICHA PROPIAMENTE. (ms. 9/7018, 20 [2-4]). 
Dentro de los Monumentos históricos concede especial importancia a aquellos que por si mismos son capaces de explicarse directamente y de instruir, como los Diplomas, y demás documentos de esta clase: inscripciones y medallas (ms. 9/7018, 6[4]). Aunque también comprende los escritores, las obras de pintura, escultura y arquitectura, así como los instrumentos, muebles y utensilios de la vida civil. En lo que a las inscripciones se refiere, Velázquez recoge una gran cantidad de textos epigráficos, siguiendo el método que él mismo indica:

De las observaciones hechas sobre cada uno de estos monumentos solo se insertaran aqui las que corresponden a su exacta descripción, a su legitimidad, a la simple declaración de sus lugares obscuros, al tiempo a que pertenecen, y al sitio en que se hallan: omitiendo enteramente las demas observaciones, que corresponden a la Historia General de España, que por ahora se reservan para en adelante (ms. 9/7018, 24 [1]).

Apartaré de ellos [de sus informes] todos aquellos monumentos mal copiados, que yo pudiese sacar de sus mismos originales, y en su lugar pondré las copias fielmente sacadas de ellos por mi, o por otras personas, que tengan a bien comunicármelas; $y$ aumentaré estas Colecciones, colocando en sus correspondientes artículos todos los demas Monumentos no publicados que yo sacase de sus originales, o de algunas copias mss. o me sean comunicadas por personas que los sacaron de las mismas fuentes. Por medio de este método estaré siempre en estado de saber, que monumentos he recogido, quales de los impresos he enmendado, y quales son los que me restan por buscar, cotejar y corregir (ms. 9/7018, 5[2-3].

En cuanto a los restos arqueológicos visitados, debemos destacar que todos los documentos de esta clase se diseñaron al vivo, y que, por primera vez, se viajaba acompañado de un dibujante. De esta manera, se trataba de evitar las falsificaciones y la copia sistemática de inscripciones. Los dibujos de buena calidad son, en la mayoría de los casos, testimonios que ayudan al estudio de los monumentos que se representan. En la documentación aporta datos sobre las medidas utilizadas - pie romano-, y sobre las distintas arquitecturas que visita, ya sean civiles (torres, castillos, acueductos, termas, etc.), de diversión pública (teatros, anfiteatros, circos, etc), de pompa pública como los arcos, religiosas como aras y templos, etc.

\section{LA EPIGRAFÍA}

En el 9/7018 la recopilación de las inscripciones latinas -de época romana y visigoda- y griegas, supone una gran parte del volumen total del manuscrito. Este aspecto nos hace reflexionar sobre la importancia que la epigrafía y el estudio de las piedras como monumento vivo de la historia de España antigua tenía dentro de las investigaciones del Marqués. Por tanto, conforme a la idea del viaje encomendado a Velázquez, la epigrafía junto con las noticias arqueológicas cumple uno de los objetivos marcados: la recopilación de lecturas, dibujos, y demás noticias que tengan valor para un mayor conocimiento y conservación de la memoria de la historia antigua peninsular.

Valdeflores recoge alrededor de ochocientas inscripciones, que aparecen en el legajo a modo de corpus epigráfico, además de otras que fueron incluidas en la redacción de las Memorias. De todas ellas, se menciona la fuente de quién las ha tomado, así como su lugar de procedencia. Una cifra menor es el conjunto de inscripciones cristianas que está al final del manuscrito, orden que responde al sentido cronológico del trabajo, criterio que caracteriza la metodología empleada por L. J. Velázquez en la elaboración de su proyecto. Aunque contamos con una gran cantidad de epígrafes, es evidente que en esta copia no se encuentran todas las inscripciones que él conocía, tal y como expresa en el folio 3 [3] la elección delos monumentos, que enel discurso de esta peregrinación debia recoger, y la manera de copiarlos, declararlos y usarlos, quedà enteramente à mi arbitrio; esta afirmación junto con el exhaustivo vaciado que hemos realizado de toda la colección Velázquez (mss. 9/4104-4159), nos reafirma en 
la idea de que eran muchas más las inscripciones con las que contaba. De hecho, en la publicación de su Noticia (Velázquez 1765: 118) nos informa que el número que recogió a lo largo de su viaje ascendía a 4.134 epígrafes.

En los folios 9[3]-10[2] explica de qué manera estructura la colección de las inscripciones que llama Colección de algunos antiguos Monumentos de la Historia de España recogidos en este Viage. Su colección se dividiría en dos partes, la primera trataría del Conocimiento y uso de las antiguas inscripciones de España, que comprende de las observaciones sacadas de las inscripciones de esta colección acerca de todas las partes de la Historia general de España, para cuio conocimiento puede ser util el uso destos monumentos; y la segunda Comprende las mismas inscripciones, y se subdivide en 4 secciones:

$1^{a}$ Seccion contiene las inscripciones de las letras desconocidas usadas en España antes de la entrada delos Romanos.

$2^{a}$ Seccion comprende las inscripciones Griegas, Egipcias y Latinas del tiempo de los Romanos hasta el fin del siglo $4^{\circ}$ y se subdivide en dos articulos.

$1^{\circ}$ articulo comprende las inscripciones Cronológicas, esto es las que señalan el tiempo, á que pertenecen, y buelbe a subdividirse en otros dos que contienen:

1. Las inscripciones de tiempo determinado, esto es, que denotan los años fixos, á que corresponden.

2. Las inscripciones de tiempo indeterminado; y en este ultimo se comprende: 1. los fragmentos de columnas Miliarias. 2. los fragmentos de las inscripciones dedicadas a los emperadores.

$2^{\circ}$ articulo contiene las inscripciones que carecen de nota cronológica; $y$ buelbe a subdividirse, en otros dos, de los quales,

1. Contiene las inscripciones griegas, y Egipcias.

2. Destinado para las latinas, comprende de 1. las inscripciones dedicadas a los Dioses. 2. las inscripciones dedicadas á las personas ilustres: 3. las inscripciones sepulcrales: 4. las delos edificios, y demas obras publicas. 5. los fragmentos, e inscripciones mal copiadas.

$3^{\text {a }}$ Seccion comprende las inscripciones del tiempo de los Godos desde el principio del siglo $5^{\circ}$ hasta el fin del siglo $7^{\circ}$ y se subdivide en dos articulos,

$1^{\circ}$ articulo comprende las inscripciones de tiempo determinado, y eneste se contienen:

1. las inscripciones del siglo $5^{\circ}$.

2. las inscripciones del siglo $6^{\circ}$.

3. las inscripciones del siglo $7^{\circ}$.

$2^{\circ}$ articulo esta destinado para las inscripciones de tiempo incierto, y que carecen de nota Cronológica.

$4^{a}$ Seccion inscripciones del tiempo medio desde la entrada de los Arabes, y principios del siglo $8^{\circ}$ hasta el año de 1516, y se subdivide en tres articulos.

$1^{\circ}$ que contiene las Inscripciones Cristianas, se divide en otros nueve articulos, destinados sucesivamente para las inscripciones del siglo $8^{\circ}$ hasta el principio del siglo $16^{\circ}$, y año de 1516.

$2^{\circ}$ comprende las inscripciones Arábigas dispuestas por orden cronológico.

$3^{\circ}$ las Hebraicas ordenadas por el mismo metodo.

El esquema que siguió para la composición de su corpus epigráfico no coincide con el contenido del manuscrito 9/7018, ya que por una parte faltan las lecturas de algunas inscripciones y, por otra, está ausente la sección cuarta dedicada a las inscripciones de tiempo de los árabes hasta el año de 1516, que encontramos en su colección (ms. 9/4106/6) y que, tal vez, perteneciese a un segundo tomo. Por ello, todo parece indicar que este legajo se corresponde con una ordenación a limpio de una parte de los apuntes recogidos a lo largo de su viaje, en los que realizó sólo una clasificación de los monumentos más destacados y pensada para su publicación, al contar con índices y notas a pie de página.

Con la entrada del siglo XVIII y el pensamiento ilustrado, el coleccionismo viene acompañado del análisis científico de los objetos, diferenciándolo sustancialmente del afán coleccionista de siglos anteriores (Beltrán 1995: 105-124; López 1995: 75-97; Lleó 1995: 57-74 e idem 1987: 21-32). El 
descubrimiento de una nueva manera de concebir la Historia contribuyó a la labor de búsqueda por parte de los ilustrados de los vestigios del pasado; los epígrafes, las medallas y todo tipo de piezas arqueológicas se convirtieron, sin duda, en los cimientos en que sustentar las Historias Nacionales de época borbónica. En los siglos anteriores se había intentado llevar a cabo trabajos de recopilación de las inscripciones de Hispania, y aunque la forma de concebir la epigrafía en plena Ilustración no difería demasiado de los siglos pasados, sí la metodología y tratamiento de las fuentes, hecho que queda reflejado en la importancia que Velázquez concede a la epigrafía (Mora 1998: 63-64; Gimeno 2003: 183-200).

La importancia de este corpus no radica tanto en la gran cantidad de inscripciones contenidas sino en el tratamiento y estudio que dedica a muchas de ellas. Debemos establecer diferencias a la hora de valorar la importancia que este manuscrito tiene para el estudio de la epigrafía en el siglo XVIII; pero ¿a qué se debe tal diferenciación? Si analizamos el itinerario que Velázquez siguió en su viaje, destacamos los dos grandes recorridos que llevó a cabo por Extremadura y Andalucía, ya que esto supone que las inscripciones procedentes de estas dos zonas tengan un mayor protagonismo con respecto a las del resto de la geografía española, ya que prácticamente todas -salvo alguna excepción- fueron recogidas y leídas directamente por él, como así lo expresa en la parte superior de cada lectura. Con respecto a las fuentes y metodología que sigue comenta lo siguiente: A la cabeza de cada una de estas inscripciones se pondrá el nombre del pueblo, y la Provincia, donde se halla; las notas de haverla yo visto, y copiado, ó el nombre de la persona de quien hubiere yo recibido su copia, expresando si la vio, y copiò, ó si la tomò de otro; las obras impresas ó mss. deque se sacasen las demas inscripciones, que no habian podido cotejarse con sus originales; las varias lecciones mas importantes, quando los libros impresos, y mss. de que se tomen, discuerden entre si; y en las inscripciones Cronologicas se señalaran al margen el año, á que corresponden (ms. 9/7018, 10 [2]).

Para la elaboración de esta obra, utilizó una larga lista de autores antiguos y contemporáneos. Con estos repertorios añade nuevos datos, que se suman, a los vastos conocimientos que tenía y complementan cada una de las materias tratadas. El abanico de fuentes utilizado abarca todo tipo de obras: impresos, manuscritos y schedae. En algunos casos, gracias a estos documentos conocemos la existencia de los epígrafes, de los cuales sólo tenemos noticia del texto a través de la tradición manuscrita. Sin embargo, queremos destacar que en ocasiones el texto proporcionado por Velázquez tras la autopsia de las piezas, constituye la editio princeps de las lecturas. Esta circunstancia se encuentra, sobre todo, en las inscripciones pertenecientes a Extremadura y Andalucía. Así, consta a finales del siglo XIX en el Corpus Inscriptionum Latinarum, en el que Emil Hübner utiliza la obra de Velázquez, en muchas ocasiones, como primera fuente $(9 / 4105$, olim ms. 12; 9/4106, olim ms. 13; 9/4110, olim ms. 17; 9/4111, olim ms. 18; 9/4118, olim ms. 25; 9/4125, olim ms. 32; 9/4131, olim ms. 38; 9/4126, olim ms. 33).

Cronológicamente las obras manejadas por Velázquez engloban los siglos XVI, XVII y XVIII. Entre los autores empleados encontramos, desde los más antiguos como Ambrosio de Morales, o de dudosa existencia como Pedro Valera ${ }^{3}$, hasta eruditos del siglo XVII como Pedro Quirós o Rodrigo Caro, o

3. L. J. Velázquez para muchas de las inscripciones que recoge utilizó el manuscrito de Pedro Valera (cfr. nota 11 del ms. 9/7018), no siendo consciente de la supuesta inexistencia de dicho autor y la falsificación de sus escritos. La creación de Pedro Valera y Alonso Franco fue atribuida a Cándido María Trigueros años más tarde (Gil 1987:153- 176). La polémica sobre la autenticidad de sus investigaciones nace con la sospecha de F. Pérez Bayer respecto a la publicación de Cándido María Trigueros sobre las inscripciones de Carmona, las cuales cree producto de su invención, (Hübner 1862: 228- 268; Stylow 2001: 95-105; Chic García 2001: 465-476). Esta cuestión se revitalizó en la segunda mitad del siglo XIX con la realización del CIL, cuando Hübner tras no poder localizar el ms. de Pedro Valera citado por Trigueros acusa a este de falsario (CIL II, p. XXII) aunque hubiese ya autoridades en la materia como T. A. Gusseme, J. A. Conde o E. Flórez, que decían haber visto dicho manuscrito, al igual que L. J. Velázquez quien dice que se lo comunicó el cordobés José Cevallos (Mora 1988: 344-348). Las falsificaciones de C. M M $^{\text {a }}$ Trigueros le han precedido a lo largo de los siglos y así quedó consolidado en la historiografía española, hasta que la actual labor de su mas ilustre biógrafo F. Aguilar Piñal (1987) ha intentado dar un vuelco a la imagen que consagró a Trigueros como uno de los mayores falsarios de la historia intelectual ilustrada de España e intenta resaltar la labor científica 
contemporáneos al propio L. J. Velázquez. La metodología empleada en la composición del corpus consistía básicamente en anotar la procedencia del hallazgo de la inscripción, la fuente de la que toma los datos y el texto propiamente dicho. En ocasiones éste va seguido de comentarios epigráficos, más o menos extensos sobre cada una de las inscripciones, restituyendo lecturas o corrigiendo los textos proporcionados por otros autores, que con anterioridad habían recogido las mismas inscripciones en sus repertorios. La erudición con respecto a la epigrafía que se refleja en las Memorias, es resultado del excelente manejo de fuentes: por un lado los corpora de autores como J. Gruter, A. Muratori o J. Estrada, obras reconocidas a nivel europeo y que eran utilizadas por todos los humanistas de la época para tal propósito y, por otro lado, los manuscritos tanto de autores extranjeros como españoles, a los cuales sólo personas de su prestigio dentro del circulo intelectual ilustrado de Madrid podrían tener acceso. A ello hay que sumarle, lamentablemente la inclusión de un importante número de textos espurios, que circulaban por los ambientes eruditos de la época, como serían los procedentes de los manuscritos de Pedro de Valera o los falsos de Granada, que tanta literatura al respecto han suscitado.

\section{LA ARQUEOLOGÍA}

En el manuscrito original que Velázquez escribió sobre su viaje (ms. 9/7018), incluyó en la parte II, Sección 2, artículo $3^{\circ}$ la descripción de los Monumentos de Escultura i Architectura, instrumentos y utensilios de la vida civil, que vio. Sobre ellos, Velázquez dice que todos los Monumentos de esta clase se representan al vivo; y a sus diseños acompaña la descripción de cada uno en particular, con la noticia del lugar donde se encuentran. Se advierte si el autor los vio e hizo diseñar, o si recibió sus diseños de mano de otras personas que los vieron, y copiaron; con la noticia de los libros impresos o MSS de que se sacan los Monumentos de esta clase que no han podido cotejarse con sus originales (Velázquez, 1765: 124).

En total, describió 49 monumentos de antigüedad, pertenecientes casi todos ellos a la época romana. En líneas generales, predomina la descripción de distintas estructuras arquitectónicas -teatros, circos, puentes, murallas, termas, etc. En la publicación de 1765 sobre su viaje, el autor indica que los monumentos, de que hasta ahora completa esta Colección, son 62, en el que se incluyen también los Monumentos de Pintura (Velázquez, 1765: 125), por lo que suponemos que sólo recogió los monumentos descritos en el manuscrito objeto de estudio.

En Emerita Augusta (Mérida, Badajoz) Velázquez permaneció durante casi cinco meses de su viaje por Extremadura, desde el 17 de diciembre de 1752 hasta el 8 de mayo de 1753, ya que era una de las ciudades de Hispania que más monumentos conservaba visibles (Salamanqués Pérez- Sánchez Medina en prensa). Desde allí, remitió a la Real Academia de la Historia algunas medallas y varios dibujos del templo de Marte a los que acompañaba una memoria, que contenía su descripción y la de otros monumentos tanto de la localidad como de otros pueblos de la provincia (Álvarez 1996: 32). Valdeflores se lamenta de la poca aficion, q(ue) hai en Extremadura a las Letras i por consiguiente a las cosas de la antigüedad, lo que le impidió recoger más medallas que las primeras q(ue) dirigi a U. (Montiano) desde Merida; $i$ aunque solicité comprar la estatua Romana, q(ue) está en Merida en poder de D. Vicente de la Rocha, pero su dueño no la quiso vender (CAG/9/7980/5/42 (8)).

Los dibujos a tinta realizados por Esteban Rodríguez de los monumentos de Mérida descritos por el Marqués de Valdeflores se guardan en la Sección de Cartografía y Bellas Artes de la Real Academia

y su aportación al pensamiento ilustrado. Actualmente faltaría profundizar en algunas cuestiones que esclarezcan este tema, no tanto las falsificaciones, en algunos casos, más que probadas por parte de Cándido María Trigueros (Aguilar Piñal 1999 e idem 2001), sino las supuestas invenciones de los escritos de Pedro Valera y Alonso Franco. 
de la Historia (BAVIe78-92), incluidos en la documentación gráfica conservada de los viajes que José Andrés Cornide de Folgueira y Saavedra inició a finales del siglo XVIII por distintos puntos de España, comisionado por la Academia (Maier 2002: 134-136). El viaje literario que Cornide se disponía a realizar por Extremadura y Portugal entre los años de 1798 y 1801 hizo que utilizase los dibujos sobre algunos monumentos de arquitectura de Mérida que se conservaban, hasta entonces, en los documentos que el mismo Velázquez remitió a la Academia sobre el viaje que había realizado entre los años de 1752 y 1753.

La descripción de los monumentos en las Memorias de Velázquez incluye los monumentos de escultura, arquitectura y de clase indeterminada y, por último, instrumentos y utensilios de la vida civil.

El propio Velázquez nos informa del trabajo que llevó a cabo en Mérida desde el 18 (de diciembre de 1752): empezé a examinar el gran numero de monumentos antiguos, q(ue) se hallan en Merida: dos puentes, dos acueductos, un Alcazar o fortaleza Romana, un circo, una Naumachia, un teatro, un tropheo, un templo, estatuas, baxos relieves, inscripciones, y otras diferentes antigüedades que se midieron, y diseñaron al vivo, usando para ello de la machina optica, siempre, que el terreno lo permitia. Además, se hicieron las excavaciones en el theatro, con el fin de descubrir casi la mitad del, que estaba cubierta de tierra (CAG/9/7980/5/42 (4). E. Rodríguez dibujó la planta (BAVIe91) y distintos alzados del teatro de Mérida, indicando antes y después de la excavación (BAVI90).

El reconocimiento de las antigüedades de Mérida incluye en los Monumentos de escultura la descripción del Templo de Marte, la Columna de Santa Eulalia, una estela funeraria con representación del difunto situada a la entrada del puente sobre el río Guadiana y dos relieves, de los que no se precisa el lugar de hallazgo. Velázquez describió los restos del Templo de Marte que coinciden con los conocidos en la actualidad, ya que fue en 1612 cuando se situaron formando un pórtico ante la capilla dedicada a la mártir Santa Eulalia. Esteban Rodríguez elaboró cuatro láminas (BAVIe 79-82) en las que dibujó los distintos elementos decorativos que se situaron en la fachada principal del templo, incluida la inscripción situada en su entablamento en la que se indica que la construcción se dedicó al dios Marte por Vettilla, mujer de Paculus (CIL II 468). Originariamente, esta inscripción contó con letras de bronce (fig. 3).

Por otra parte, describió tres de las aras, dos anepigráficas y una con inscripción, que formaron la columna del monumento de Santa Eulalia, fechado en el siglo I d C. El ara votiva con mención a la Concordia (CIL II 465) sustentó el llamado obelisco de Santa Eulalia. En la cara posterior del ara se grabó esta piedra con las letras de la Concordia de Augusto se halló en la plaza de Santiago, cavando una ruina de romanos, año de 1646. Un poco más tarde, en 1652 se inauguró la nueva ubicación del monumento tal y como lo conocemos hoy. La Real Academia de la Historia conserva dos dibujos a tinta en un pliego con el título Triunfo de Santa Eulalia compuesta por tres aras romanas decoradas con bucráneos y guirnaldas, que pertenecen al viaje literario de José Cornide (BAVIe78).

El mayor número de Monumentos de arquitectura catalogados en sus Memorias corresponde a Mérida. Describió con detalle el recinto amurallado con el que contó la capital de la Lusitania y mandó dibujarlo (BAVIe87). También detalló las dimensiones y el número de arcos del puente sobre el río Anas (Guadiana) y sobre el Albarregas. En este último puente se iniciaba el iter ab Emerita Asturicam, la llamada Vía de la Plata (Álvarez y Nogales 2004: 255-276). De ambos puentes se conservan sendos dibujo a tinta (BAVIe84 y 85). A continuación, y siguiendo el orden marcado por Velázquez en su descripción, se interesó por el sistema de abastecimiento de agua a la ciudad, detallando los acueductos de los Milagros y de San Lázaro, con sus correspondientes dibujos (BAVIe88 y 89) y describió los edificios para espectáculos con los que contó la ciudad de Mérida: el teatro (Salas - León 2003-2005: 87-91), el anfiteatro y el circo (BAVIe 90, 91 y 92). Velázquez consideró que los restos conservados del anfiteatro de Mérida se correspondían con los de una naumachia, advirtiendo que se trataba del único edificio de estas características hallado, hasta el momento, en España.

ISSN: 1133-4525 ISSN-e: 2255-3924

SPAL 14 (2005)

http://dx.doi.org/10.12795/spal.2005.i14.01 


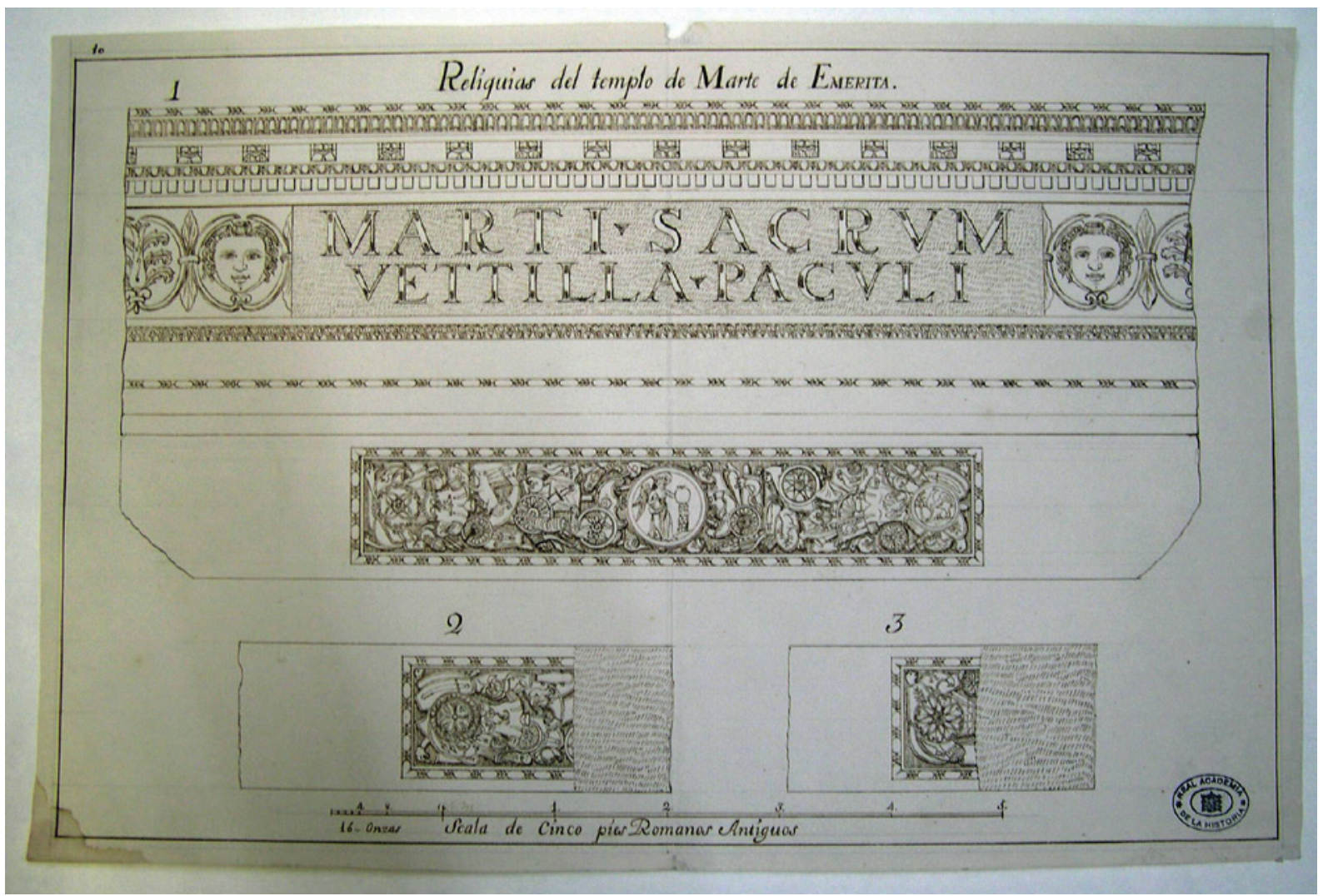

Fig. 3. Dibujo a plumilla de la fachada del templo de Marte en Mérida, realizado por Esteban Rodríguez. RAH Cartografía BAVIe82.

En el viaje a Mérida se alude al arco de Santiago (arco de Trajano). Velázquez afirma que no se trata de un arco triunfal, ya que estuvo unido por ambos laterales a otros edificios (BAVIe 75). Por último, describe un edificio de carácter religioso, del que se desconoce la divinidad a la que estaba dedicada. El denominado Templo de Diana fue ocupado, desde el siglo XVI, por una mansión señorial, la Casa de los Milagros, y prácticamente su apariencia no ha variado desde el viaje que realizase el Marqués de Valdeflores (BAVIe 83).

El 8 de mayo de 1753, tras haber obtenido el preceptivo permiso del rey para salir de Extremadura, proyectó su viaje hasta Salamanca, con el fin de examinar el camino de la plata (CAG/9/7980/5/42(4). El itinerario que siguió lo detalló en el informe que remitió a Montiano desde Granada pero, en ningún momento, abandonó Extremadura. Así sabemos que permaneció en Alcántara (Cáceres) entre los días 10 y 14 de mayo donde se midió y diseñó el puente, y templo antiguo que está sobre el; y recogí algunas inscripciones examinando otras, q(ue) se decian haver alli cerca, en la hermita de N. S. de los Hitos, y en la de S. Jordan. En el manuscrito que estudiamos describe la construcción del puente situado sobre el río Tajo y las inscripciones que mencionan a su arquitecto, C. Iulius Lacer (CIL II 761-762), situadas en el arco triunfal colocado en la parte central del puente. Muchos han sido los autores que se han ocupado del puente de Alcántara, entre ellos Laborde, Ceán Bermúdez y E. Hübner. El Marqués de Valdeflores lo mandó dibujar en 1793. En el tomo XXV de su colección, titulado Observaciones del viage de Extremadura y Andaluzia, describió el puente de Alcántara (ms. 9/4118). Su descripción se incluye dentro de su estudio histórico: II. Provincia de Extremadura de León, y $p^{a}$ del $r^{o} d^{e}$ León, folios 17 a 20. También realizó la descripción 
del pequeño templo, dedicado a César, situado en el lado izquierdo del puente, que fue construido por el mismo arquitecto (CIL II 761).

El 15 de mayo se detuvo en Coria donde describió la muralla que rodeaba la ciudad, junto con sus cuatro puertas y las torres que se situaron en su trazado. Al día siguiente, visitó la ermita de Nuestra Señora de Fuentes Dueñas localizando un sarcófago sin tapa y la inscripción sarco/s pater/c situada en las gradas de su altar. Prosiguió su viaje hasta Caparra donde llegó el día 17 de mayo. Allí detalló los restos de un arco conmemorativo, erigido por M. Fidio Macer, según la disposición testamentaria de sus padres Fidio Macrio y Bolosea, hija de Pelio (CIL II 834). Velázquez consideró que se trataba de un monumento funerario y lo incluyó en el apartado $11^{\circ}$ Sarcophagos y Sepulcros (ms 9/7018/102 [3-4] y $103[1])$.

Velázquez continuó su viaje deteniéndose el 30 de mayo de 1753 en Zalamea de la Serena (Badajoz). En el antiguo municipium Iulipense se conservan los restos de un edificio romano, posiblemente un templo, que se utilizaron para la construcción de la torre de la iglesia de Zalamea. Velázquez describe el basamento de sillería y dos columnas, y un miliario con dedicación a Trajano, que forma parte de la pila bautismal en el interior de la iglesia. La descripción del monumento de Zalamea de la Serena la incluye en los Monumentos de Arquitectura de clase indeterminada, aunque piensa que pudo corresponder a un monumento funerario, por su similitud con el sepulcro de Cáparra (Cáceres). El primer dibujo que realizó Velázquez de este monumento se conserva en su colección (9/4131/47), al igual que el de Esteban Rodríguez (ms. 9/4128/22) (fig. 4).

El 2 de junio de 1753, Velázquez visitó Alange donde descubrí unas termas, o Baños antiguos, q(ue) se diseñaron, i midieron $i$ se copió otra inscripción (CAG/9/7980/5/42 (7)). Explicó las construcciones que formaron parte de unas termas, haciendo hincapié en las propiedades medicinales de sus aguas e hizo mención del ara votiva dedicada a la diosa Iuno, que se halló en ellas (CIL II 1024). En nota, Velázquez nos informa de que se realizó un dibujo de las termas de Alange (ms. 9/4128/44).

El 27 de junio regresó a Mérida tras haber recogido las inscripciones y descrito los monumentos antiguos encontrados a su paso. Desde este día empezé a proyectar la Relacion del viage de toda la Provincia, y a disponer el Mapa de ella; $i$ en ejecutar lo uno i lo otro me detube alli hasta el 7 de Septiembre, en q(ue) sali para Andalucía. Cuando iniciaba el viaje hacia Andalucía se detuvo en Usagre (Badajoz), el 8 de septiembre de 1753, donde descubrí un baxo reliebe con su inscripción (CAG/9/7980/5/42 (7). En la actualidad, se conserva en la fachada de la iglesia parroquial del municipio, donde la vio Velázquez.

Presumiblemente, este primer viaje debía completarse con la inspección de los monumentos de antigüedad de Toledo, en Castilla la Nueva, y parte del Reyno de León hasta cerca de Salamanca. Sin embargo, en el manuscrito de Velázquez sólo se menciona los restos de un circo junto al convento de San Bartolomé en Toledo y la descripción de una espada, conservada en el Monasterio de la Sisla (Toledo).

El 10 de septiembre de 1753 inició su segundo viaje, que se prolongó hasta el último día del año de 1754. En Sevilla visitó los gabinetes del duque de Alcalá y Francisco de Bruna (Romero y Murube 1965: 97-141). Destacó la importante colección de monumentos antiguos de escultura que se conservaban en el palacio de los duques de Alcalá, procedentes, en su mayor parte, de Roma. De ellos, describió el ara dedicada a Isis (CIL II 3386) hallada en Guadix (fig. 5) y una pesa con mención de Q. Iunius Rusticus. En el gabinete de Francisco de Bruna examinó el pedestal de estatua que se encontró en 1762 en Las Cabezas de San Juan durante la construcción de una iglesia y de cuyo hallazgo informó a la Academia Tomás Andrés de Gusseme (Cebrián 2002: 84).

Durante su estancia en Sevilla, visitó Italica (Santiponce). Las excavaciones en esta antigua ciudad se iniciaron a finales del siglo XVIII, por lo que Velázquez sólo vio parte del anfiteatro, no pudiendo ofrecernos ni siquiera sus dimensiones. Por otra parte, describe un ara con inscripción bilingüe hallada cerca de Lora del Río, aunque advierte que copia de los manuscritos de P. Valera, falsa según E. Hübner

ISSN: 1133-4525 ISSN-e: 2255-3924

SPAL 14 (2005)

http://dx.doi.org/10.12795/spal.2005.i14.01 


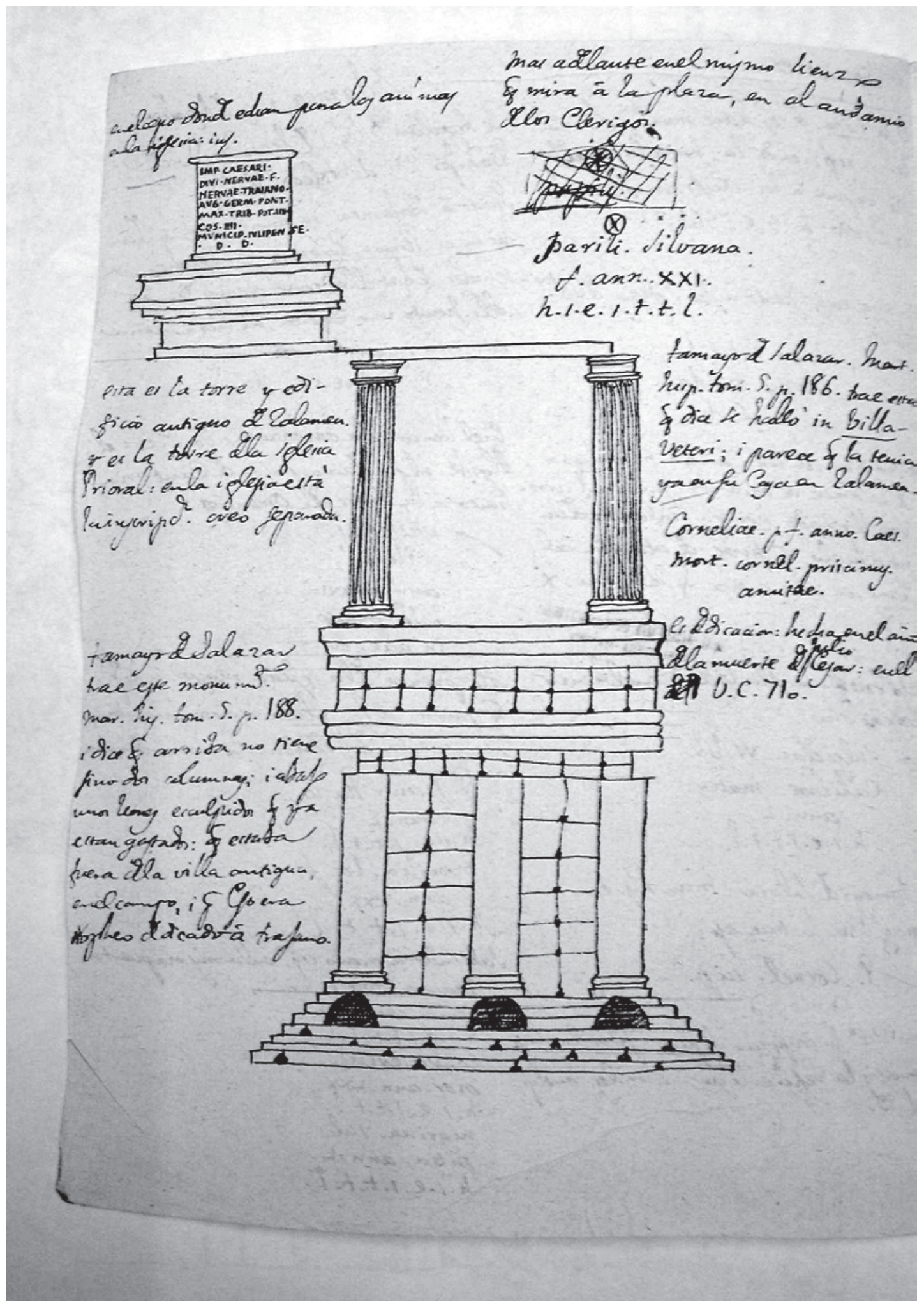

Fig. 4. Monumento funerario de Zalamea de la Serena (Badajoz) diseñado por Luis José Velázquez. RAH ms. 9/4131/44. 
(CIL II 108*). Por último, recoge una urna cineraria con inscripción, que se encuentra en poder de Gusseme, del que copia su diseño, hallada en Las Mezquitillas (CIL II 4968, 8).

La recopilación de los monumentos en el Reino de Sevilla que realiza Velázquez durante su viaje prosigue en Antequera (Málaga), donde describe un ara con relieves en todas sus caras, que se encuentra en la Puerta de los Gigantes. En esta misma localidad, visita la casa del Marqués de Estepa, que conserva un relieve con la imagen del ciervo de Diana e inscripción, hallado en Lorilla (Almagro-Gorbea 2003: 415). El Marqués de Valdeflores copió el dibujo de este ara de los manuscritos de Valera. Además, describió el teatro de la antigua Singilia Barba (Cortijo del Castillón, Antequera), del que dice fue destruido, en su mayor parte, para la construcción del Convento de San Juan de Dios.

El Marqués de Valdeflores redujo la mansio Portus Albus a un despoblado situado cerca de Algeciras llamado Alcarria, donde permanecen las ruinas de una antigua población romana. Describe dos relieves con motivos animales e inscripción griega y latina, que Hübner considera falsas (CIL II 151*). La información la toma de Pedro Valera, con lo que suponemos que no vio estos dos relieves. En Medina Sidonia (Cádiz) describió un sarcófago marmóreo con inscripción (CIL II 1320), conservado en la sacristía del Convento de los Franciscanos. También copió el dibujo de una vasija con inscripción, hallada en Sanlúcar la Mayor.

Visitó el teatro de Acinipo (Ronda la Vieja, Málaga) en tres ocasiones, una el 21 de octubre de 1747, otra el 11 de enero de 1750 y la última en 1754 dentro de su Viaje Literario, para realizar la descripción y el dibujo de sus restos (ms. 9/5994, 125-161) que, hasta entonces, sólo habían sido realizados por Rodrigo Caro. En Málaga, visitó el gabinete de Manuel Trabuco, que conservaba una pesa romana hallada junto a Churriana y un anillo con inscripción griega, encontrado en el valle de Abdalajís. En Marbella, describió los restos de una villa junto al mar, que incluía un acueducto, una almadraba y un pequeño edificio realizado con argamasa.

En Granada se dirigió a los gabinetes de Pedro de la Cueva y al de Juan de Flores, los cuales poseían estatuas de bronce. Mientras en Córdoba realizó una descripción de sus murallas, de sus torres, del acueducto y de los pedestales situados en la puerta principal de entrada a la ciudad.

Por último, en este manuscrito se hace referencia al sacellum erigido por Q. Iulius Celsus, cerca de la ermita de San Bartolomé en Martos (Jaén), aunque Velázquez dice que no vio este templo sino que lo copió.

Entre los monumentos descritos por Velázquez de otras provincias españolas se incluye un sarcófago marmóreo conservado en el patio de una casa de Barcelona, un medallón de oro con figura de Hércules céltico sin procedencia, una estatua de época moderna descubierta en 1627 en Zaragoza durante las obras del colegio de la Compañía de Jesús, una estatua egipcia, una con representación de Ceres y otra con figura de Mercurio en bronce, conservadas en el Real Gabinete de Historia Natural de Madrid, cuyas inscripciones ya copió, y el acueducto de Segovia.

\section{VALORACIÓN}

La Real Academia de la Historia impulsó el viaje que el Marqués de Valdeflores debía realizar por toda la geografía española con el propósito de recopilar las fuentes necesarias para formar la historia de España. Este viaje destacó por el carácter arqueológico que Velázquez imprimió a las descripciones de los Monumentos de Antigüedad que realizó, en las que tuvieron mucho que ver los dibujos de Esteban Rodríguez. Empleó técnicas topográficas para medir los edificios romanos que se conservaban en Mérida y se interesó por el conocimiento de la medida utilizada por los romanos en sus construcciones. El propio Velázquez relata que en una de las jornadas de su viaje a Extremadura realizó las medidas de las Millas, para averiguar el verdadero tamaño del pie Español antiguo, y la extensión de las 


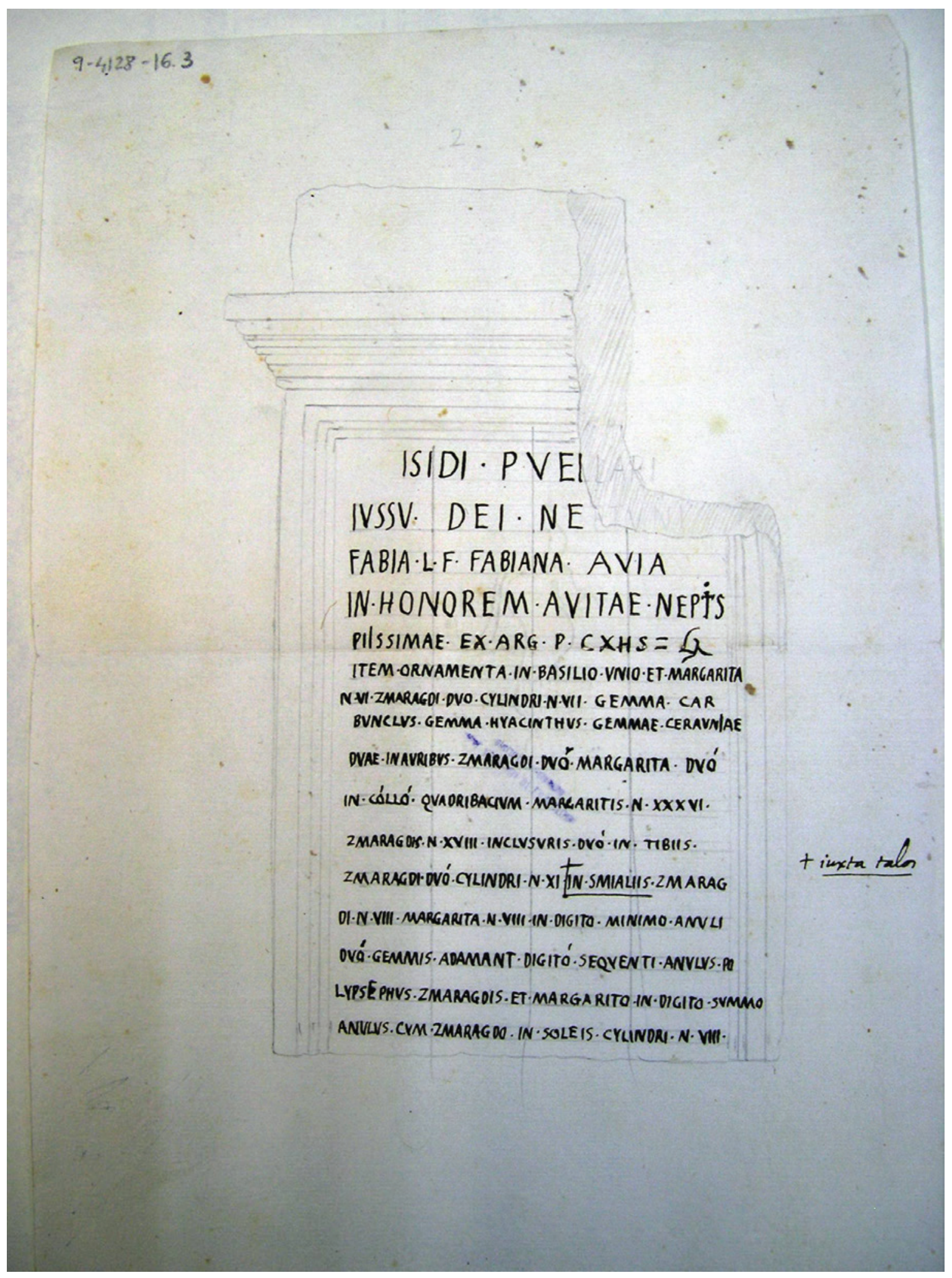

Fig. 5. Dibujo a lápiz y a tinta del ara dedicada a Isis que se halla en Guadix (Granada), realizado por Velázquez. RAH ms. 9-4128-16. 
millas Romanas, concretamente el día 21 de mayo de 1753, desde Valverde por la Calzada hasta Baños (CAG/9/7980/5/42(3)).

Ahora sabemos que el marqués de Valdeflores sólo viajó durante los años de 1752 a 1754. El itinerario que siguió en su viaje a Extremadura se encuentra en una carta escrita al Director de la Real Academia de la Historia, Agustín de Montiano, desde Granada y fechada el 2 de octubre de 1753, en la que además le informa de que ya dispone de la Relación de el viage de Extremadura y, que una vez realizada una copia, remitirá el texto a aquella institución (ms. 9/4118).

Conocemos su estancia en Sevilla, Málaga y Granada durante el viaje que realizó por Andalucía gracias a las anotaciones y dibujos que se conservan en su colección (ms. 9/4128). La labor de recopilación de los Monumentos de Antigüedad conservados en Andalucía comenzó con la visita de Velázquez a los gabinetes particulares del duque de Alcalá y Francisco de Bruna en Sevilla, Manuel Trabuco en Málaga o los de Pedro de la Cueva y Juan de Flores en Granada, de los que obtuvo gran parte de la información que utilizó para escribir el capítulo dedicado a los Monumentos de Escultura i Architectura, instrumentos y utensilios de la vida civil en la memoria de su viaje.

\section{BIBLIOGRAFÍA}

ABASCAL, J. M. y CEBRIÁN, R. (2005): Manuscritos sobre Antigüedades, Madrid. AGUILAR PIÑAL, F. (1987): Un escritor ilustrado: Cándido María Trigueros, Madrid.

_- (1999): La Biblioteca y Monetario del Académico Cándido María Trigueros (1798), Sevilla.

- (2001): El académico Cándido María Trigueros (1736-1798), Madrid.

ALMAGRO-GORBEA, M. (2003): Epigrafia prerromana, Madrid.

ÁlVAREZ MARTÍ-AGUILAR, M. (1996): La Antigüedad en la Historiografia española del s. XVIII: El Marqués de Valdeflores, Málaga.

ÁLVAREZ MARTÍNEZ, J. Ma y NOGALES, T. (2004): "Calzada de Lusitania: programación e ideología imperial", en Actas V Mesa Redonda Internacional sobre Lusitania romana: Las comunicaciones, Madrid: 255-276.

BELTRÁN FORTES, J (1995): "Entre la erudición y el coleccionismo: anticuarios andaluces de los siglos XVI al XVIII", en La Antigüedad como argumento. Historiografía de Arqueología e Historia Antigua en Andalucía, (eds. J. Beltrán - F. Gascó), Sevilla: 105-124.

CEBRIÁN, R. (2002): Comisión de Antigüedades de la Real Academia de la Historia. Antigüedades e Inscripciones, 1748-1845. Catálogo e Índices, Madrid.

CHIC GARCÍA, G (2001): "Religión, territorio y economía en la Carmo romana", en Carmona Romana, Sevilla: $465-476$.

FLORES DE ODDOUZ, J. Monumentos descubiertos en la Antigua Illiberia, Illipula, o Granata, en Virtud de las Reales Ordenes de S.M.C, (Biblioteca Nacinal, R/39420).

GIL, J. (1987): "Epigrafía Antigua y moderna” Habis 12: 153- 176.

GIMENO PASCUAL, H. (2003): "Avances y retrocesos de una disciplina: ilustrados españoles ante la epigrafía" en, Illuminismo e Ilustración le Antichità e i loro protagonista in Spagna e in Italia nel XVIII secolo, (eds. J. Beltrán - B. Cacciotti - X. Dupré - B Palma), Roma: 183-200.

HÜBNER, E. (1862): “Trigueros und Franco, zwei Spanische Inschriftensammler”, Rheinisches Museum für Philologie 17: 228- 268.

LLEÓ CAÑAL, V (1987): "El jardín arqueológico del primer duque de Alcalá", Fragmentos 11: 21-32.

- (1995): "Origen y función de las primeras colecciones renacentistas de antigüedades en Andalucía", en La Antigüedad como argumento. Historiografía de Arqueología e Historia Antigua en Andalucía, (ed. J. Beltrán - F. Gascó), Sevilla: 57-74.

ISSN: $1133-4525$ ISSN-e: 2255-3924

SPAL 14 (2005)

http://dx.doi.org/10.12795/spal.2005.i14.01 
LÓPEZ RODRÍGUEZ, J. R (1995): "Sevilla, el nacimiento de los museos, América y la Botánica", en La Antigüedad como argumento. Historiografia de Arqueología e Historia Antigua en Andalucía, (ed. J. Beltrán - F. Gascó), Sevilla: 75-97.

MAIER, J. (2002): Comisión de Antigüedades de la Real Academia de la Historia. Documentación General. Catálogo e Índices, Madrid.

MORA, G. (1988): “Trigueros y Hübner. Algunas notas sobre el concepto de falsificación”, Archivo Español de Arqueología 61: 344-348.

MORA, G. (1998): "Historias de mármol. La Arqueología clásica española en el siglo XVIII", Anejos de Archivo Español de Arqueología XVIII, Madrid.

ROMERO Y MURUBE, J. (1965): Francisco de Bruna y Ahumada, Sevilla.

SALAMANQUÉS PÉREZ, V., - SÁNCHEZ MEDINA, E. (en prensa) : "Un paysage de ruines à Mérida du XVIIIe siècle d'après L. J. Velázquez: monuments et inscriptions", en $130^{e}$ congrès des sociétés historiques et scientifiques. Voyages et voyageurs. Université de La Rochelle. Poitou-Charentes. Francia. 18-23 de abril de 2005.

SALAS ÁLVAREZ, J., - LEÓN GÓMEZ, A. (2003-2005): "La representación gráfica de la Antigüedad clásica emeritense durante la Ilustración. El ejemplo del teatro romano", en El nacimiento de la Prehistoria y de la Arqueología Cientifica, (ed. V. Cabrera Valdés - M. Ayarzagüena Sanz), Archaia. Revista de la Sociedad española de Historia de la Arqueología 3-5: 86- 103.

STYLOW, A. U. (2001): "Una aproximación a la Carmo romana a través de su epigrafía. Nuevas aportaciones y revisión crítica", en Carmona Romana. Actas del II Congreso de Historia de Carmona: Carmona, 29 de Septiembre a 2 de Octubre de 1999 (ed. A. Caballos Rufino) Sevilla, 95-105.

VELÁZQUEZ, L. J. (1759): Conjeturas sobre las medallas de los reyes Godos, y Suevos de España, Málaga.

(1759): Anales de la Nación española desde el tiempo más remoto hasta la entrada de los romanos, sacados unicamente de los escritores y Monumentos originales, i contemporáneos, Málaga.

- (1765): Noticia del viage de España hecho de orden del Rey. Y de una nueva historia general de la nación desde el tiempo más remoto hasta el año de 1516. sacada unicamente de los Escritores y Monumentos originales, y contemporáneos. Con la colección universal de estos mismo Escritores, y Monumentos recogidos en este Viage, Madrid. 
APÉNDICE I

\begin{tabular}{|c|c|c|c|}
\hline CIL II & Folios & Procedencia & Fuente \\
\hline $0010^{*}$ & $40[4]$ & Évora (Portugal) & $\begin{array}{l}\text { Mss. de P. Valera. En nota, CIL II } 454 \text { de L. } \\
\text { A. Muratori, y los mss. ambrosianos }\end{array}$ \\
\hline $0017^{*}$ & $58[2]$ & San Lúcar la Mayor (Sevilla) & Mss. de R. Caro \\
\hline $0066^{*}$ & $41[1]$ & Medellín (Badajoz) & L. J. Velázquez \\
\hline $0069 *$ & $40[3]$ & Trujillo (Cáceres) & Mss. de P. Valera \\
\hline $0073 *$ & $59[4]$ & Alcántara (Cáceres) & L. J. Velázquez \\
\hline $0074 *$ & $46[2]$ & Alcántara (Cáceres) & L. J. Velázquez \\
\hline $0108^{*}$ & $39[4]$ & Lorilla (Sevilla) & Mss. de P. Valera \\
\hline $0109 *$ & $42[3]$ & Lora (Sevilla) & Mss. de P. Valera \\
\hline $0112 *$ & $44[3]$ & Santiponce (Sevilla) & Mss. de P. Valera \\
\hline $0113^{*}$ & $44[3]$ & Cerca de Sevilla (Sevilla) & Mss. de P. Valera \\
\hline $0116^{*}$ & $55[3]$ & $\begin{array}{c}\text { Benazuza (San Lúcar la Mayor, } \\
\text { Sevilla) }\end{array}$ & Mss. de R. Caro \\
\hline 0119* & $104[4]$ & Sanlúcar la Mayor (Sevilla) & L. J. Velázquez \\
\hline $0120^{*}$ & $\begin{array}{l}63[3]- \\
63[4]\end{array}$ & $\begin{array}{l}\text { Salteras, a dos leguas al } \\
\text { occidente de Sevilla }\end{array}$ & Sin fuente \\
\hline $0121 *$ & $59[1]$ & Espartiñas (Sevilla) & Ms. de P. Quirós \\
\hline $0126^{*}$ & $\begin{array}{l}71[3]- \\
71[4] \\
\end{array}$ & $\begin{array}{l}\text { Villamartín (Arcos de la } \\
\text { Frontera, Cádiz) }\end{array}$ & Mss. de R. Caro \\
\hline 0146 & $\begin{array}{l}57[4]- \\
58[1]\end{array}$ & Villavisosa (Portugal) & $\begin{array}{l}\text { Mss. de H. Soarez y de L. A. Muratori, éste } \\
\text { de los mss. ambrosianos que pone la inscrip- } \\
\text { ción en Cáparra (Cáceres), y de los mss. Far- } \\
\text { nesianos, con diferente lectura y que ubican } \\
\text { en Talavera (Toledo) }\end{array}$ \\
\hline $0151 *$ & $44[2]$ & Algeciras (Cádiz) & Mss. de P. Valera \\
\hline $0168^{*}$ & $35[1]$ & Málaga (Málaga) & P. Morejón Historia de Málaga manuscrita \\
\hline $0170^{*}$ & $46[3]$ & Málaga (Málaga) & P. Morejón Historia de Málaga manuscrita \\
\hline $0171 *$ & $77[2]$ & Málaga (Málaga) & P. Morejón Historia de Málaga manuscrita \\
\hline $0172 *$ & $71[4]$ & Málaga (Málaga) & P. Morejón Historia de Málaga manuscrita \\
\hline $0244^{*}$ & $58[1]$ & Cifuentes (Guadalajara) & Ms. de J. F. A. de Uztarroz \\
\hline $0282 *$ & $42[2]$ & Toledo (Toledo) & $\begin{array}{l}\text { Mss. de P. Valera. En nota recoge, según él, } \\
\text { mal copiados, de T. Tamayo de Vargas y P. de } \\
\text { Rojas, Conde de Mora. Esta inscripción ya la } \\
\text { había visto y copiado correctamente P. Valera } \\
\text { en } 1589\end{array}$ \\
\hline $0286^{*}$ & $59[3]$ & Sitio a dos leguas de Toledo & Mss. de P. Valera \\
\hline $0342 *$ & $25[2]$ & Cazlona (Jaén) & Mss. de P. Valera \\
\hline $0342 *$ & $\begin{array}{c}45[1] \\
\text { y nota } \\
17\end{array}$ & Cazlona (Jaén) & Mss. de P. Valera \\
\hline
\end{tabular}




\begin{tabular}{|c|c|c|c|}
\hline CIL II & Folios & Procedencia & Fuente \\
\hline $0343^{*}$ & $54[2]$ & $\begin{array}{c}\text { despoblado que dicen de } \\
\text { Cazlona, junto a Linares(Jaén) }\end{array}$ & Mss. de P. Valera \\
\hline $0409 *$ & $\begin{array}{l}45[2]- \\
45[3]\end{array}$ & Caldes (Barcelona) & Mss. de P. Valera \\
\hline $0424 *$ & $40[4]$ & Vich (Barcelona) & Mss. de P. Valera \\
\hline 0464 & $79[3]$ & Mérida (Badajoz) & De quien la vio y copió \\
\hline 0465 & $41[1]$ & Mérida (Badajoz) & L. J. Velázquez \\
\hline 0465 & $85[4]$ & Mérida (Badajoz) & L. J. Velázquez \\
\hline 0466 & $41[2]$ & Mérida (Badajoz) & L. J. Velázquez \\
\hline 0468 & $43[4]$ & Mérida (Badajoz) & L. J. Velázquez \\
\hline 0468 & $83[2]$ & Mérida (Badajoz) & L. J. Velázquez \\
\hline 0476 & $31[1]$ & Mérida (Badajoz) & L. J. Velázquez \\
\hline 0486 & $29[2]$ & Mérida (Badajoz) & L. J. Velázquez \\
\hline 0486 Tachada & $65[2]$ & Mérida (Badajoz) & L. J. Velázquez \\
\hline 0488 & $55[3]$ & $\begin{array}{l}\text { Torremejía, llevada de la ciudad } \\
\text { de Mérida (Badajoz) }\end{array}$ & L. J. Velázquez \\
\hline 0491 & $67[2]$ & Mérida (Badajoz) & L. J. Velázquez \\
\hline 0497 & $65[2]$ & Mérida (Badajoz) & L. J. Velázquez \\
\hline 0499 & $59[2]$ & Mérida (Badajoz) & L. J. Velázquez \\
\hline 0500 & $46[4]$ & Mérida (Badajoz) & L. J. Velázquez \\
\hline 0505 & $64[4]$ & Mérida (Badajoz) & L. J. Velázquez \\
\hline 0506 & $66[1]$ & $\begin{array}{c}\text { Torremejía, llevada de la ciudad } \\
\text { de Mérida (Badajoz) }\end{array}$ & L. J. Velázquez \\
\hline 0508 & $69[2]$ & $\begin{array}{c}\text { Madrid, llevada de la ciudad de } \\
\text { Mérida (Badajoz) }\end{array}$ & L. J. Velázquez \\
\hline 0511 & $66[4]$ & Mérida (Badajoz) & L. J. Velázquez \\
\hline 0512 & $81[3]$ & Mérida (Badajoz) & L. J. Velázquez \\
\hline 0515 & $66[1]$ & Mérida (Badajoz) & L. J. Velázquez \\
\hline 0523 & $70[1]$ & Mérida (Badajoz) & L. J. Velázquez \\
\hline 0528 & $55[4]$ & Mérida (Badajoz) & L. J. Velázquez \\
\hline 0531 & $56[2]$ & $\begin{array}{c}\text { Torremejía, llevada de la ciudad } \\
\text { de Mérida (Badajoz) }\end{array}$ & L. J. Velázquez \\
\hline 0540 & $59[2]$ & Mérida (Badajoz) & L. J. Velázquez \\
\hline 0553 & $61[3]$ & Mérida (Badajoz) & L. J. Velázquez \\
\hline 0556 & $63[4]$ & Mérida (Badajoz) & L. J. Velázquez \\
\hline 0557 & $64[2]$ & Mérida (Badajoz) & L. J. Velázquez \\
\hline 0558 & $64[3]$ & Mérida (Badajoz) & L. J. Velázquez \\
\hline 0559 & $64[3]$ & Mérida (Badajoz) & L. J. Velázquez \\
\hline 0564 & $65[1]$ & Mérida (Badajoz) & L. J. Velázquez \\
\hline
\end{tabular}




\begin{tabular}{|c|c|c|c|}
\hline CIL II & Folios & Procedencia & Fuente \\
\hline 0565 & $65[1]$ & $\begin{array}{l}\text { Torremejía, llevada de la ciudad } \\
\text { de Mérida (Badajoz) }\end{array}$ & L. J. Velázquez \\
\hline 0566 & $\begin{array}{l}65[2]- \\
65[3]\end{array}$ & Mérida (Badajoz) & L. J. Velázquez \\
\hline 0572 & $66[1]$ & Mérida (Badajoz) & L. J. Velázquez \\
\hline 0577 & $68[1]$ & Mérida (Badajoz) & L. J. Velázquez \\
\hline 0579 & $68[3]$ & Mérida (Badajoz) & L. J. Velázquez \\
\hline 0580 & $69[1]$ & Mérida (Badajoz) & L. J. Velázquez \\
\hline 0585 & $75[2]$ & Mérida (Badajoz) & L. J. Velázquez \\
\hline 0586 & $70[2]$ & Mérida (Badajoz) & L. J. Velázquez \\
\hline 0587 & $70[2]$ & Mérida (Badajoz) & L. J. Velázquez \\
\hline 0602 & $75[4]$ & Mérida (Badajoz) & L. J. Velázquez \\
\hline 0605 & $79[4]$ & Medellín (Badajoz) & L. J. Velázquez \\
\hline 0607 & $30[3]$ & Medellín (Badajoz) & L. J. Velázquez \\
\hline 0610 & $32[2]$ & Medellín (Badajoz) & L. J. Velázquez \\
\hline 0611 & $71[4]$ & Medellín (Badajoz) & L. J. Velázquez \\
\hline 0613 & $69[1]$ & Medellín (Badajoz) & L. J. Velázquez \\
\hline 0620 & $44[4]$ & Trujillo (Cáceres) & Mss. de P. Valera \\
\hline 0693 & $35[4]$ & Cáceres (Cáceres) & L. J. Velázquez \\
\hline 0695 & $52[3]$ & Cáceres (Cáceres) & L. J. Velázquez \\
\hline 0704 & $64[4]$ & Cáceres (Cáceres) & L. J. Velázquez \\
\hline 0705 & $\begin{array}{l}65[3]- \\
65[4] \\
\end{array}$ & Cáceres (Cáceres) & L. J. Velázquez \\
\hline 0712 & $69[2]$ & Cáceres (Cáceres) & L. J. Velázquez \\
\hline 0713 & $69[2]$ & Cáceres (Cáceres) & L. J. Velázquez \\
\hline 0717 & $81[1]$ & Cáceres (Cáceres) & L. J. Velázquez \\
\hline 0748 & $59[2]$ & Brozas (Cáceres) & L. J. Velázquez \\
\hline 0757 & $56[1]$ & $\begin{array}{c}\text { Ermita de Ntra. Sra. de los Hitos, } \\
\text { a media legua al oriente de la } \\
\text { villa de Alcántara (Cáceres) }\end{array}$ & L. J. Velázquez \\
\hline 0759 & $33[1]$ & $\begin{array}{c}\text { Puente de Alcántara (Alcántara, } \\
\text { Cáceres) }\end{array}$ & L. J. Velázquez \\
\hline 0760 & $91[4]$ & Alcántara (Cáceres) & A. Morales \\
\hline 0761 & $\begin{array}{l}33[1]- \\
33[2]\end{array}$ & Alcántara (Cáceres) & L. J. Velázquez \\
\hline 0761 & $33[3]$ & Alcántara, (Cáceres) & L. J. Velázquez \\
\hline $0761-0762$ & $92[1]$ & Alcántara (Cáceres) & L. J. Velázquez \\
\hline 0770 & $\begin{array}{l}81[3]- \\
81[4]\end{array}$ & Coria (Cáceres) & L. J. Velázquez \\
\hline 0771 & $55[4]$ & Coria (Cáceres) & L. J. Velázquez \\
\hline
\end{tabular}




\begin{tabular}{|c|c|c|c|}
\hline CIL II & Folios & Procedencia & Fuente \\
\hline 0773 & $67[4]$ & Coria (Cáceres) & L. J. Velázquez \\
\hline 0781 & $63[4]$ & Coria (Cáceres) & L. J. Velázquez \\
\hline 0788 & $76[1]$ & Coria (Cáceres) & L. J. Velázquez \\
\hline 0790 & $75[3]$ & Coria (Cáceres) & L. J. Velázquez \\
\hline 0805 & $44[2]$ & Caparra (Cáceres) & L. J. Velázquez \\
\hline 0808 & $46[1]$ & Oliva, llevada de Caparra & L. J. Velázquez \\
\hline 0814 & $74[1]$ & $\begin{array}{l}\text { Abadía, llevada de la aldea de } \\
\text { Caparra (Cáceres) }\end{array}$ & $\begin{array}{l}\text { Memorias hitóricas y genealógicas de los } \\
\text { Duques de Alba, de J. de Lezaun. También la } \\
\text { recoge L. A. Muratori }\end{array}$ \\
\hline 0817 & $79[2]$ & $\begin{array}{l}\text { Oliva, junto a Plasencia, llevada } \\
\text { de la aldea de Caparra (Cáceres) }\end{array}$ & L. J. Velázquez \\
\hline 0818 & $55[2]$ & $\begin{array}{l}\text { Oliva,junto a Plasencia, llevada } \\
\text { de Caparra }\end{array}$ & L. J. Velázquez \\
\hline 0823 & $71[2]$ & $\begin{array}{l}\text { Oliva, junto a Plasencia, llevada } \\
\text { de la aldea de Caparra (Cáceres) }\end{array}$ & L. J. Velázquez \\
\hline 0827 & $71[3]$ & $\begin{array}{l}\text { Oliva, junto a Plasencia, llevada } \\
\text { de la aldea de Caparra (Cáceres) }\end{array}$ & L. J. Velázquez \\
\hline 0829 & $61[1]$ & $\begin{array}{l}\text { Oliva, junto a Plasencia, llevada } \\
\text { de la aldea de Caparra (Cáceres) }\end{array}$ & L. J. Velázquez \\
\hline 0832 & $57[4]$ & $\begin{array}{c}\text { Abadía, llevada de la aldea de } \\
\text { Caparra (Cáceres) }\end{array}$ & A. M. Burriel de un ms. antiguo \\
\hline 0834 & $58[3]$ & Caparra (Cáceres) & $\begin{array}{l}\text { L. J. Velázquez. También la recoge de la obra } \\
\text { de A. Occo (p. II, 2) }\end{array}$ \\
\hline 0834 & $102[4]$ & Caparra (Cáceres) & $\begin{array}{l}\text { L. J. Velázquez } \\
\end{array}$ \\
\hline 0836 & $63[2]$ & $\begin{array}{l}\text { Oliva, junto a Plasencia, llevada } \\
\text { de la aldea de Caparra (Cáceres) }\end{array}$ & L. J. Velázquez \\
\hline 0846 & $81[3]$ & $\begin{array}{l}\text { Oliva, junto a Plasencia, llevada } \\
\text { de la aldea de Caparra (Cáceres) }\end{array}$ & L. J. Velázquez \\
\hline 0849 & $75[4]$ & $\begin{array}{l}\text { Oliva, junto a Plasencia, llevada } \\
\text { de la aldea de Caparra (Cáceres) }\end{array}$ & L. J. Velázquez \\
\hline 0850 & $80[3]$ & $\begin{array}{l}\text { Oliva, junto a Plasencia, llevada } \\
\text { de la aldea de Caparra (Cáceres) }\end{array}$ & L. J. Velázquez \\
\hline 0853 & $57[3]$ & Plasencia (Cáceres) & A. M. Burriel \\
\hline 0854 & $102[2]$ & Plasencia (Cáceres) & L. J. Velázquez \\
\hline 0860 & $43[1]$ & Ciudad Rodrigo (Salamanca) & F. Pérez Bayer \\
\hline 0865 & $79[2]$ & Ciudad Rodrigo (Salamanca) & F. Pérez Bayer \\
\hline 0874 & $81[4]$ & Salamanca (Salamanca) & F. Pérez Bayer \\
\hline 0880 & $56[1]$ & $\begin{array}{l}\text { Torrecilla de Aldea Tejada, junto } \\
\text { a la ciudad de Salamanca }\end{array}$ & F. Pérez Bayer \\
\hline 0896 & $56[2]$ & Lugar incierto & Pastor \\
\hline 0897 & $61[2]$ & Procedencia incierta & Pastor, de quien la vio y copió \\
\hline
\end{tabular}




\begin{tabular}{|c|c|c|c|}
\hline CIL II & Folios & Procedencia & Fuente \\
\hline 0899 & $73[1]$ & Talavera de la Reina (Toledo) & A. M. Burriel \\
\hline 0907 & $63[1]$ & Talavera de la Reina (Toledo) & A. M. Burriel \\
\hline 0912 & $50[3]$ & Procedencia incierta & Pastor \\
\hline 0918 & $68[4]$ & $\begin{array}{c}\text { Lugar incierto (actualmente en } \\
\text { Talavera, Toledo) }\end{array}$ & Pastor, de quien la vio y copió \\
\hline 0934 & $69[4]$ & $\begin{array}{c}\text { Lugar incierto, actualmente en } \\
\text { Talavera (Toledo) }\end{array}$ & A. M. Burriel, de quien la vio y copió \\
\hline 0951 & $29[3]$ & Trigueros (Huelva) & Mss . de R. Caro \\
\hline 0956 & $32[3]$ & $\begin{array}{c}\text { Minas de Río Tinto (Río Tinto, } \\
\text { Huelva) }\end{array}$ & T. A. de Gusseme \\
\hline 0964 & $47[2]$ & Aroche (Huelva) & Mss. de R. Caro \\
\hline 0984 & $77[1]$ & Zafra (Badajoz) & Mss. de R. Caro \\
\hline 0985 & $80[1]$ & Burguillos (Badajoz) & De quien la vio y copió \\
\hline 0988 & $73[2]$ & Zafra (Badajoz) & Mss. de R. Caro \\
\hline 0992 & $57[2]$ & Zafra (Badajoz) & Mss. de R. Caro \\
\hline 0993 & $45[6]$ & Zafra (Badajoz) & Mss. de R. Caro \\
\hline 0997 & $45[6]$ & Zafra (Badajoz) & Mss. de R. Caro \\
\hline 0997 & $45[6]$ & $\begin{array}{l}\text { Convento de Santo Domingo del } \\
\text { Campo, cerca de Alconera }\end{array}$ & De quien la vio, y copió \\
\hline 0998 & $64[2]$ & Parra (Badajoz) & De quien la vio y copió \\
\hline 0999 & $\begin{array}{l}64[1]- \\
64[2]\end{array}$ & Burguillos (Badajoz) & $\begin{array}{l}\text { L. J. Velázquez, dos lecturas de las misma } \\
\text { inscripción, de Caro, de quien la vio y copió }\end{array}$ \\
\hline 1000 & $65[3]$ & Alconera (Badajoz) & De quien la vio y copió \\
\hline 1002 & $45[6]$ & Zafra (Badajoz) & Mss. de R. Caro \\
\hline 1004 & $68[1]$ & Zafra (Badajoz) & Mss. de R. Caro \\
\hline 1008 & $81[1]$ & Burguillos (Badajoz) & De quien la vio y copió \\
\hline 1010 & $72[4]$ & $\begin{array}{c}\text { Convento del Domingo del } \\
\text { Campo, media legua de la } \\
\text { Alconera (Badajoz) }\end{array}$ & De quien la vio y copió \\
\hline 1011 & $73[3]$ & Burguillos (Badajoz) & De quien la vio y la copió \\
\hline 1012 & $\begin{array}{l}74[2]- \\
74[3] \\
\end{array}$ & Salvatierra (Cáceres) & De quien la vio y copió \\
\hline 1024 & $43[2]$ & Alange (Badajoz) & L. J. Velázquez \\
\hline 1024 & $94[1]$ & Alange (Badajoz) & L. J. Velázquez \\
\hline 1026 & $45[5]$ & Medina de las Torres (Badajoz) & Mss. de R. Caro \\
\hline 1026 & $\begin{array}{l}45[5]- \\
45[6]\end{array}$ & Medina de las Torres (Badajoz) & Mss. de R. Caro \\
\hline 1026 & $45[6]$ & Medina de las Torres (Badajoz) & Mss. de R. Caro \\
\hline 1029 & $67[3]$ & Zafra (Badajoz) & Mss. de R. Caro \\
\hline 1030 & $65[4]$ & $\begin{array}{l}\text { En las ruinas entre Fuente de } \\
\text { Cantos (Badajoz) y Calzadilla }\end{array}$ & Mss. de R. Caro \\
\hline
\end{tabular}




\begin{tabular}{|c|c|c|c|}
\hline CIL II & Folios & Procedencia & Fuente \\
\hline 1031 & $61[4]$ & Medina de las Torres (Badajoz) & Mss. de R. Caro \\
\hline 1032 & $57[3]$ & Medina de las Torres (Badajoz) & Mss. de R. Caro \\
\hline 1041 & $81[4]$ & Monasterio (Badajoz) & L. J. Velázquez \\
\hline 1049 & $32[1]$ & Castillo de Mulva (Sevilla) & T. A. De Gusseme \\
\hline 1050 & $32[1]$ & Castillo de Mulva (Sevilla) & T. A. De Gusseme \\
\hline 1052 & $80[4]$ & Mulva (Sevilla) & T. A. de Gusseme \\
\hline 1053 & $46[3]$ & Castillo de Mulva (Sevilla) & T. A. de Gusseme \\
\hline 1054 & $50[3]$ & Lora del Río (Sevilla) & T. A. de Gusseme \\
\hline 1062 & $45[4]$ & Alcolea (Sevilla) & T. A. de Guseme \\
\hline 1064 & $49[3]$ & $\begin{array}{c}\text { Despoblado Piedra de la Sal, } \\
\text { entre Lora del Río y Alcolea } \\
\text { (Sevilla) }\end{array}$ & T. A. de Gusseme \\
\hline 1066 & $48[4]$ & $\begin{array}{c}\text { Despoblado Piedra de la Sal, } \\
\text { entre Lora del Río y Alcolea, } \\
\text { cerca del río Guadalquivir, reino } \\
\text { de Sevilla }\end{array}$ & T. A. de Gusseme \\
\hline 1068 & $49[1]$ & Alcolea, villa del Reino de Sevilla & T. A. de Gusseme \\
\hline 1070 & $70[4]$ & Alcolea del Río (Sevilla) & T. A. de Gusseme \\
\hline 1071 & $\begin{array}{c}77[2]- \\
77[3]\end{array}$ & $\begin{array}{c}\text { Ermita de Ntra. Sra. de Setefilla } \\
\text { en el despoblado de este nombre, } \\
\text { a dos leguas de Lora del Río y } \\
\text { dos leguas y media de Peñaflor } \\
\text { (Sevilla) }\end{array}$ & T. A. de Gusseme \\
\hline 1074 & $\begin{array}{l}77[3]- \\
77[4]\end{array}$ & Alcolea del Río (Sevilla) & T. A. de Gusseme \\
\hline $1075 \mathrm{~b}$ & $77[4]$ & Alcolea del Río (Sevilla) & T. A. de Gusseme \\
\hline 1081 & $55[4]$ & $\begin{array}{l}\text { Sevilla (Sevilla), llevada de la } \\
\text { Villa de Cantillana }\end{array}$ & L. I. Leirens \\
\hline 1082 & $38[4]$ & Alcalá del Río (Sevilla) & Mss. de A. Carrillo \\
\hline 1088 & $\begin{array}{c}58[4]- \\
59[1] \\
\end{array}$ & Alcalá del Río (Sevilla) & L. J. Velázquez \\
\hline 1089 & $61[1]$ & Alcalá del Río (Sevilla) & L. J. Velázquez \\
\hline 1091 & $51[2]$ & Alcalá del Río (Sevilla) & Mss. de A. Carrillo \\
\hline 1098 & $64[1]$ & Alcalá del Río (Sevilla) & Mss. de A. Carrillo \\
\hline 1116 & 38 [2] & Santiponce (Sevilla) & L. J. Velázquez \\
\hline 1117 & 38 [2] & Santiponce (Sevilla) & L. J. Velázquez \\
\hline 1133 & $29[2]$ & Santiponce (Sevilla) & L. J. Velázquez \\
\hline 1147 & $62[3]$ & Santiponce (Sevilla) & L. J. Velázquez \\
\hline 1149 & $63[4]$ & $\begin{array}{c}\text { Toledo, llevada de Santiponce } \\
\text { (Sevilla) }\end{array}$ & L. J. Velázquez \\
\hline
\end{tabular}




\begin{tabular}{|c|c|c|c|}
\hline CIL II & Folios & Procedencia & Fuente \\
\hline 1157 & $75[4]$ & Santiponce (Sevilla) & L. J. Velázquez \\
\hline 1168 & $35[1]$ & Sevilla (Sevilla) & L. J. Velázquez \\
\hline 1170 & $36[2]$ & Sevilla (Sevilla) & L. I. Leirens \\
\hline 1171 & $38[3]$ & Sevilla (Sevilla) & L. J. Velázquez \\
\hline 1172 & $60[4]$ & Sevilla (Sevilla) & L. I. Leirens \\
\hline 1174 & $\begin{array}{c}48[4]- \\
49[1]\end{array}$ & Sevilla (Sevilla) & L. I. Leirens \\
\hline 1178 & $\begin{array}{c}47[3]- \\
47[4] \\
\end{array}$ & Sevilla (Sevilla) & L. I. Leirens \\
\hline 1179 & $29[2]$ & Sevilla & L. J. Velázquez \\
\hline 1182 & $51[2]$ & Sevilla (Sevilla) & L. I. Leirens \\
\hline 1183 & $48[1]$ & Sevilla (Sevilla) & L. I. Leirens \\
\hline 1184 & $49[4]$ & Sevilla (Sevilla) & L. I. Leirens \\
\hline 1200 & $62[2]$ & Sevilla (Sevilla) & L. I. Leirens \\
\hline 1211 & $57[1]$ & Sevilla (Sevilla) & Mss. de R. Caro \\
\hline 1212 & $57[1]$ & Sevilla (Sevilla) & L. I. Leirens \\
\hline 1217 & $58[1]$ & Sevilla (Sevilla) & L. I. Leirens, que la vio y copió \\
\hline 1220 & $72[1]$ & Sevilla (Sevilla) & Mss. de R. Caro \\
\hline 1221 & $61[4]$ & Sevilla (Sevilla) & Mss. de R. Caro \\
\hline 1227 & $63[1]$ & Sevilla (Sevilla) & T. A. de Gusseme, de quien la vió y copió \\
\hline 1228 & $62[2]$ & Sevilla (Sevilla) & Mss. de R. Caro \\
\hline 1230 & $65[4]$ & Sevilla (Sevilla) & Mss. de R. Caro \\
\hline 1230 Tachada & $50[1]$ & Sevilla (Sevilla) & Mss. de R. Caro \\
\hline 1242 & $73[2]$ & Sevilla (Sevilla) & Mss. de R. Caro \\
\hline 1252 & $76[1]$ & Sevilla (Sevilla) & L. I. Leirens \\
\hline 1254 & $35[4]$ & Salteras (Sevilla) & Mss. de R. Caro \\
\hline 1255 & $80[3]$ & Salteras (Sevilla) & Mss. de R. Caro \\
\hline 1256 & $47[2]$ & Sevilla (Sevilla) & L. I. Leirens \\
\hline 1258 & $48[2]$ & Sevilla (Sevilla) & L. J. Velázquez \\
\hline 1260 & $55[2]$ & Espartiñas (Sevilla) & Mss. de Quiroga \\
\hline 1265 & $62[1]$ & Tocina $($ Sevilla $)$ & T. A. de Gusseme \\
\hline 1266 & $31[4]$ & San Lúcar la Mayor (Sevilla) & Mss. de R. Caro \\
\hline 1270 & $79[2]$ & Huevar (Sevilla) & Mss. de R. Caro \\
\hline 1271 & $51[2]$ & Palomares (Sevilla) & Mss. de R. Caro \\
\hline 1272 & $64[4]$ & Castilleja del Campo (Sevilla) & Mss. de R. Caro \\
\hline 1273 & $61[3]$ & Castilleja del Campo (Sevilla) & Mss. de R. Caro \\
\hline 1274 & $60[3]$ & Campillos (Sevilla) & Mss. de R. Caro \\
\hline
\end{tabular}




\begin{tabular}{|c|c|c|c|}
\hline CIL II & Folios & Procedencia & Fuente \\
\hline 1277 & $51[3]$ & $\begin{array}{c}\text { Cortijo Suerte Lozana, junto } \\
\text { al despoblado de Sarracatin, } \\
\text { dos leguas y media de Utrera } \\
\text { (Sevilla) }\end{array}$ & L. I. Leirens \\
\hline 1297 & $65[3]$ & Lebrija (Sevilla) & L. J. Velázquez \\
\hline 1299 & $72[2]$ & $\begin{array}{l}\text { A media legua de Lebrija } \\
\text { (Sevilla) }\end{array}$ & L. I. Leirens, de quien la vio y copió \\
\hline 1301 & $44[1]$ & $\begin{array}{l}\text { Las Cabezas de San Juan } \\
\text { (Sevilla) }\end{array}$ & J. Estrada \\
\hline 1302 & $31[1]$ & $\begin{array}{l}\text { Las Cabezas de San Juan } \\
\text { (Sevilla) }\end{array}$ & L. I. Leirens \\
\hline 1304 & $42[2]$ & Jerez de la Frontera (Cádiz) & Mss. de R. Caro \\
\hline 1306 & $80[1]$ & Jerez de la Frontera (Cádiz) & T. A. de Gusseme \\
\hline 1307 & \begin{tabular}{|l}
$55[4]-$ \\
$56[1]$ \\
\end{tabular} & Jerez de la Frontera (Cádiz) & $\begin{array}{l}\text { T. A. de Gusseme, esta piedra está copiada en } \\
\text { dos piedras diferentes. }\end{array}$ \\
\hline 1308 & $74[1]$ & $\begin{array}{c}\text { En el despoblado que dicen de } \\
\text { Alcántara junto a Jerez de la } \\
\text { Frontera (Cádiz) }\end{array}$ & Mss. de R. Caro \\
\hline 1309 & $75[3]$ & Jerez de la Frontera (Cádiz) & E. Trabuco, de quien la vio y copió \\
\hline 1312 & $46[1]$ & Medina Sidonia (Málaga) & L. J. Velázquez \\
\hline 1313 & $47[1]$ & Medina Sidonia (Cádiz) & L. J. Velázquez \\
\hline 1317 & $48[1]$ & Medina Sidonia (Cádiz) & L. J. Velázquez \\
\hline 1320 & $87[2]$ & Medina Sidonia (Cádiz) & P. Concepción \\
\hline 1324 & $49[2]$ & Medina Sidonia (Cádiz) & L. J. Velázquez \\
\hline 1327 & $66[3]$ & Medina Sidonia (Cádiz) & L. J. Velázquez \\
\hline 1330 & $79[3]$ & Jimena de la Frontera (Cádiz) & L. J. Velázquez \\
\hline 1332 & $35[3]$ & Jimena (Jaén) & L. J. Velázquez \\
\hline 1333 & $81[1]$ & $\begin{array}{c}\text { Jimena (Jimena de la Frontera, } \\
\text { Cádiz) }\end{array}$ & L. J. Velázquez \\
\hline 1345 & $45[5]$ & $\begin{array}{l}\text { Ronda la Vieja (Málaga), a } \\
\text { media legua de Setenil de las } \\
\text { Bodegas (Cádiz) }\end{array}$ & L. J. Velázquez \\
\hline 1346 & $41[3]$ & $\begin{array}{c}\text { Ronda la Vieja, ruinas media } \\
\text { legua de Setenil de las Bodegas } \\
\text { (Granada) }\end{array}$ & L. J. Velázquez \\
\hline 1348 & $51[4]$ & $\begin{array}{l}\text { Ronda la Vieja (Granada), a } \\
\text { media legua de Setenil de las } \\
\text { Bodegas }\end{array}$ & Mss. de R. Caro \\
\hline 1350 & $49[1]$ & Ronda (Granada) & E. Trabuco \\
\hline 1350 & $51[4]$ & $\begin{array}{l}\text { Ronda la Vieja (Granada), a } \\
\text { media legua de Setenil de las } \\
\text { Bodegas }\end{array}$ & Mss. de R. Caro \\
\hline
\end{tabular}




\begin{tabular}{|c|c|c|c|}
\hline CIL II & Folios & Procedencia & Fuente \\
\hline 1351 & $80[2]$ & $\begin{array}{c}\text { Setenil de las Bodegas, llevada } \\
\text { del despoblado que dicen de } \\
\text { Ronda La Vieja (Málaga) }\end{array}$ & L. J. Velázquez \\
\hline 1359 & $50[2]$ & Ronda (Granada) & Mss. de M. Fariña \\
\hline 1364 & $47[3]$ & Arcos de la Frontera (Sevilla) & J. Estrada \\
\hline 1366 & $69[1]$ & $\begin{array}{c}\text { Cortijo que dicen Casa Blanca a } \\
\text { una legua y media al mediodia de } \\
\text { Arcos, (Sevilla) }\end{array}$ & T. A. de Gusseme \\
\hline 1378 & $46[3]$ & Carmona (Sevilla) & P. Villaceballos \\
\hline 1379 & $49[2]$ & Carmona (Sevilla) & T. A. de Gusseme \\
\hline 1379 & $79[4]$ & Carmona (Sevilla) & A. M. Burriel, de quien la vio y copió \\
\hline 1380 & $50[2]$ & Carmona (Sevilla) & $\begin{array}{l}\text { L. I. Leirens. También en las Antigüedades de } \\
\text { Sevilla de R. Caro }\end{array}$ \\
\hline 1386 & $69[4]$ & Carmona (Sevilla) & $\begin{array}{l}\text { P. Villaceballos } \\
\end{array}$ \\
\hline 1389 & $67[3]$ & Fuentes (Sevilla) & P. Villaceballos \\
\hline 1392 & $31[4]$ & Marchena (Sevilla) & T. A. De Gusseme \\
\hline 1401 & $70[4]$ & Marchena (Sevilla) & Mss. de R. Caro \\
\hline 1421 & $72[3]$ & Puebla de Cazalla (Sevilla) & Mss. de R. Caro \\
\hline 1439, II $2 / 5$, p. 266 & $35[2]$ & Lorilla $($ Sevilla $)$ & De quien lo vio, y copió \\
\hline 1440 & $38[4]$ & Lorilla, junto a Antequera (Sevilla) & De quien lo vio, y copió \\
\hline 1450 & $\begin{array}{l}69[3]- \\
69[4]\end{array}$ & $\begin{array}{c}\text { Lorilla (Sevilla), junto a } \\
\text { Antequera, llevada de la villa de } \\
\text { Estepa }\end{array}$ & De quien la vio y copió \\
\hline 1532 & $81[1]$ & Montemayor (Córdoba) & Mss. de J. Fernández Franco \\
\hline 1632 & $68[4]$ & $\begin{array}{c}\text { Despoblado de Torre de Zambra, } \\
\text { entre la villa de Rute y la ciudad } \\
\text { de Lucena (Córdoba) }\end{array}$ & $\begin{array}{l}\text { F. de Cabrera, Historia de Antequera } \\
\text { manuscrita }\end{array}$ \\
\hline 1666 & $102[1]$ & Martos (Jaén) & De mano de una persona \\
\hline 1701 & $64[1]$ & Martos (Jaén) & Mss. de D. de Villalta \\
\hline 1737 & $55[4]$ & Chiclana (Cádiz) & L. J. Velázquez \\
\hline 1821 & $64[3]$ & Cádiz (Cádiz) & P. M. Carbonel \\
\hline 1844 & $67[1]$ & $\begin{array}{l}\text { Málaga (Málaga), llevada de la } \\
\text { ciudad de Cádiz }\end{array}$ & L. J. Velázquez \\
\hline 1874 & $\begin{array}{l}71[2]- \\
71[3]\end{array}$ & Chiclana (Cádiz) & L. J. Velázquez \\
\hline 1881 & $71[4]$ & $\begin{array}{l}\text { Córdoba (Córdoba), llevada de } \\
\text { la ciudad de Cádiz }\end{array}$ & L. J. Velázquez \\
\hline 1895 & $\begin{array}{l}74[1]- \\
74[2]\end{array}$ & $\begin{array}{l}\text { Málaga (Málaga), llevada de la } \\
\text { ciudad de Cádiz }\end{array}$ & L. J. Velázquez \\
\hline 1905 & $74[4]$ & Cádiz (Cádiz) & P. M. Carbonel \\
\hline 1906 & $75[2]$ & Cádiz & Pastor, de quien la vio y copió \\
\hline
\end{tabular}




\begin{tabular}{|c|c|c|c|}
\hline CIL II & Folios & Procedencia & Fuente \\
\hline 1924 & $54[1]$ & $\begin{array}{l}\text { Bejel de la Miel (Sevilla), llevada } \\
\text { de las antiguas ruinas a la } \\
\text { desembocadura del río Barbate }\end{array}$ & L. J. Velázquez \\
\hline 1930 & $73[4]$ & Algeciras (Cádiz) & Mss. de M. Fariña \\
\hline 1931 & $74[1]$ & Rocadillo (Cádiz) & E. Trabuco, de quien la vio y copió \\
\hline 1932 & $81[4]$ & Rocadillo (Cádiz) & E. Trabuco, de quien la vio y copió \\
\hline 1934 & $41[3]$ & $\begin{array}{l}\text { Casares (Granada), llevada de } \\
\text { Alechipe, ruina a media legua de } \\
\text { alli, hacia el occidente }\end{array}$ & L. J. Velázquez \\
\hline 1935 & $43[2]$ & $\begin{array}{c}\text { Alechipe, ruinas a media legua } \\
\text { al occidente de Casares, villa del } \\
\text { Reino de Granada }\end{array}$ & Mss. de M. Fariña \\
\hline 1936 & $51[4]$ & $\begin{array}{l}\text { Casares (Granada), llevada del } \\
\text { despoblado de Alechipe }\end{array}$ & L. J. Velázquez \\
\hline 1938 & $43[4]$ & Gibraltar & Mss. de M. Fariña \\
\hline 1945 & $32[2]$ & Alora (Málaga) & $\begin{array}{l}\text { E. Trabuco copiada de L. A. Muratori (p. } 229,4) \\
\text { y este de los mss. farnesianos y capponios }\end{array}$ \\
\hline 1946 & $35[2]$ & $\begin{array}{l}\text { Cortijo de Almendral, cerca de } \\
\text { Cártama (Málaga) }\end{array}$ & L. J. Velázquez \\
\hline 1947 & $54[3]$ & $\begin{array}{l}\text { Antequera (Málaga) llevada de la } \\
\text { villa de Alora }\end{array}$ & L. J. Velázquez \\
\hline 1949 & $43[4]$ & Cártama (Málaga) & L. J. Velázquez \\
\hline 1951 & $45[3]$ & Cártama (Málaga) & L. J. Velázquez \\
\hline 1952 & $45[3]$ & Cártama (Málaga) & L. J. Velázquez \\
\hline 1954 & $48[3]$ & Cártama (Málaga) & L. J. Velázquez \\
\hline 1955 & $50[2]$ & Cártama (Málaga) & L. J. Velázquez \\
\hline 1956 & $50[1]$ & Cártama (Málaga) & L. J. Velázquez \\
\hline 1957 & $53[1]$ & Cártama (Málaga) & L. J. Velázquez \\
\hline 1957 & $\begin{array}{l}70[3]- \\
70[4]\end{array}$ & Cártama (Málaga) & L. J. Velázquez \\
\hline 1958 & $54[3]$ & Cártama (Málaga) & L. J. Velázquez \\
\hline 1959 & $48[3]$ & Cártama (Málaga) & L. J. Velázquez \\
\hline 1971 & $54[1]$ & Málaga (Málaga), en la Alcazaba & L. J. Velázquez \\
\hline 1978 & $44[1]$ & Adra (Granada) & E. Trabuco \\
\hline 1978 & $\begin{array}{l}51[3]- \\
51[4]\end{array}$ & Adra (Almería) & E. Trabuco \\
\hline 1979 & $\begin{array}{l}60[2]- \\
60[3] \\
\end{array}$ & $\begin{array}{l}\text { Málaga (Málaga), llevada de la } \\
\text { ciudad de Cádiz }\end{array}$ & L. J. Velázquez \\
\hline 1981 & $47[1]$ & Adra (Granada) & E. Trabuco \\
\hline 1985 & $56[4]$ & Adra (Granada) & E. Trabuco \\
\hline 1989 & $67[4]$ & Adra (Granada) & E. Trabuco, de quien la vio y copió \\
\hline
\end{tabular}




\begin{tabular}{|c|c|c|c|}
\hline CIL II & Folios & Procedencia & Fuente \\
\hline 2008 & $82[1]$ & Valle de Abdalajis (Málaga) & M. Ruiz \\
\hline 2159 & $47[1]$ & $\begin{array}{c}\text { Córdoba (Córdoba), llevada de } \\
\text { la villa de Montoro }\end{array}$ & L. J. Velázquez \\
\hline 2160 & $47[2]$ & Montoro (Córdoba) & T. A. de Gusseme \\
\hline 2292 & $67[4]$ & $\begin{array}{l}\text { Córdoba (Córdoba), llevada de } \\
\text { la villa de Peñaflor (Sevilla) }\end{array}$ & L. J. Velázquez \\
\hline $\begin{array}{l}\text { 2304CIL II2/7, p. } \\
65\end{array}$ & $72[2]$ & $\begin{array}{c}\text { Córdoba, (actualmente de } \\
\text { Peñaflor, Sevilla) }\end{array}$ & L. J. Velázquez \\
\hline 2323 & $56[1]$ & $\begin{array}{c}\text { Almodóvar del Pinar, } \\
\text { actualmente en Casasimarro } \\
\text { (Cuenca) }\end{array}$ & A. M. Burriel, de quien la vio y la copió \\
\hline 2336 & $75[3]$ & $\begin{array}{l}\text { Córdoba (Córdoba), llevada de } \\
\text { la villa de Peñaflor (Sevilla) }\end{array}$ & L. J. Velázquez \\
\hline 2354 & $59[4]$ & Zalamea de la Serena (Badajoz) & L. J. Velázquez \\
\hline 2426 & $71[3]$ & Braga (Portugal) & Mss. de J. Romano \\
\hline 2726 & $46[3]$ & Valladolid (Valladolid) & A. Eximeno \\
\hline 2772 & $43[2]$ & $\begin{array}{l}\text { La Coruña, es de Coruña del } \\
\text { Conde (Burgos) }\end{array}$ & A. M. Burriel \\
\hline 2782 & $29[2]$ & Coruña del Conde (Cuenca) & A. M. Burriel \\
\hline 2785 & $75[1]$ & $\begin{array}{l}\text { La Coruña, es de Coruña del } \\
\text { Conde (Burgos) }\end{array}$ & A. M. Burriel \\
\hline 2786 & $57[4]$ & $\begin{array}{l}\text { La Coruña, es de Coruña del } \\
\text { Conde (Burgos) }\end{array}$ & A. M. Burriel \\
\hline 2787 & $55[3]$ & Coruña del Conde (Burgos) & A. M. Burriel \\
\hline 2844 & $75[1]$ & $\begin{array}{c}\text { Entre Villaciervos y Catañazas } \\
\text { (Soria) }\end{array}$ & $\begin{array}{c}\text { J. F. A. de Uztarroz, Zaragoza antigua } \\
\text { manuscrita }\end{array}$ \\
\hline 2912 & $\begin{array}{l}57[1]- \\
57[2]\end{array}$ & Herrera de Pisuerga (Palencia) & A. M. Burriel \\
\hline 2915 & $77[1]$ & Sasamón (Burgos) & A. M. Burriel, de quien la vio y copió \\
\hline 2943 & $42[1]$ & Fuengirola (Málaga) & L. J. Velázquez \\
\hline $\begin{array}{l}2973 \text { y } 55061 \mathrm{II} 2 / 5 \\
0623\end{array}$ & $35[3]$ & Granada (Granada) & L. J. Velázquez \\
\hline 2978 & $56[4]$ & $\begin{array}{c}\text { Puiarraso, junto a "un Castillo", } \\
\text { actualmente Uncastillo } \\
\text { (Zaragoza) }\end{array}$ & $\begin{array}{c}\text { J. F. A. de Uztarroz, Zaragoza antigua } \\
\text { manuscrita }\end{array}$ \\
\hline 2981 & $70[4]$ & $\begin{array}{l}\text { A tres leguas de Ejea de los } \\
\text { Caballeros (Zaragoza) }\end{array}$ & $\begin{array}{c}\text { J. F. A. de Uztarroz, Zaragoza antigua } \\
\text { manuscrita }\end{array}$ \\
\hline 2986 & $73[3]$ & Tarazona (Zaragoza) & $\begin{array}{l}\text { J. F. A. de Uztarroz, Zaragoza antigua } \\
\text { manuscrita, de una copia de J. Zurita, } \\
\text { procede de un libro de inscripciones que tenía } \\
\text { el Conde de Guimerá. }\end{array}$ \\
\hline
\end{tabular}




\begin{tabular}{|c|c|c|c|}
\hline CIL II & Folios & Procedencia & Fuente \\
\hline 2991 & $42[1]$ & Zaragoza (Zaragoza) & $\begin{array}{c}\text { J. F. A. de Uztarroz, Zaragoza antigua } \\
\text { manuscrita, de una copia de J. Zurita, } \\
\text { procede de un libro de inscripciones que tenía } \\
\text { el Conde de Guimerá }\end{array}$ \\
\hline 2995 & $68[2]$ & Zaragoza (Zaragoza) & $\begin{array}{c}\text { J. F. A. de Uztarroz, Zaragoza antigua } \\
\text { manuscrita }\end{array}$ \\
\hline 2997 & $74[3]$ & Zaragoza (Zaragoza) & $\begin{array}{c}\text { J. F. A. de Uztarroz, Zaragoza antigua } \\
\text { manuscrita }\end{array}$ \\
\hline 3015 & $67[1]$ & Velilla (Zaragoza) & $\begin{array}{c}\text { J. F. A. de Uztarroz, Zaragoza antigua } \\
\text { manuscrita }\end{array}$ \\
\hline 3016 & $73[4]$ & Velilla (Zaragoza) & $\begin{array}{c}\text { J. F. A. de Uztarroz, Zaragoza antigua } \\
\text { manuscrita }\end{array}$ \\
\hline 3018 & $49[2]$ & Chiprana (Zaragoza) & Mss. de V. J. de Lastanosa \\
\hline 3035 & $79[3]$ & Alcalá de Henares (Madrid) & A. M. Burriel \\
\hline 3036 & $66[2]$ & Alcalá de Henares (Madrid) & L. J. Velázquez \\
\hline 3037 & $72[1]$ & $\begin{array}{c}\text { Torrejón de Ardoz (Madrid), } \\
\text { llevada de un sitio inmediato que } \\
\text { va desde Madrid a la ciudad de } \\
\text { Alcalá de Henares }\end{array}$ & A. M. Burriel \\
\hline 3039 & $57[4]$ & Alcalá de Henares (Madrid) & A. M. Burriel \\
\hline $\begin{array}{l}3039 \text { Tachada, cfr. } \\
\text { f. } 57 \text { [4]. }\end{array}$ & $58[4]$ & Alcalá de Henares (Madrid) & A. M. Burriel \\
\hline 3067 & $44[3]$ & $\begin{array}{c}\text { Arganda (Madrid), llevada de } \\
\text { Valtierra }\end{array}$ & $\begin{array}{l}\text { Mss. de P. Valera. En nota recoge las } \\
\text { variantes de lectura de A. de Morales y P. de } \\
\text { Rojas, Conde de Mora. }\end{array}$ \\
\hline 3073 & $37[3]$ & Toledo (Toledo) & L. J. Velázquez \\
\hline 3074 & $58[2]$ & Toledo (Toledo) & A. M. Burriel \\
\hline 3079 & $56[3]$ & Escalonilla (Toledo) & A. M. Burriel \\
\hline 3080 & $74[4]$ & Maqueda (Toledo) & A. M. Burriel, de quien la vio y copió \\
\hline 3085 & $68[4]$ & Carmena (Toledo) & A. M. Burriel \\
\hline 3114 & $79[4]$ & $\begin{array}{c}\text { Cabeza de Griego, Saelices } \\
\text { (Cuenca) }\end{array}$ & A. M. Burriel, de quien la vio y copió \\
\hline 3123 & $\begin{array}{l}57[3]- \\
57[4]\end{array}$ & $\begin{array}{c}\text { Cabeza de Griego, Saelices } \\
\text { (Cuenca) }\end{array}$ & A. M. Burriel \\
\hline 3166 & $71[1]$ & Sacedón (Cuenca) & A. M. Burriel, de quien la vio y copió \\
\hline 3167 & $78[1]$ & $\begin{array}{l}\text { En el sitio que llaman Peña } \\
\text { Escrita, cerca de Cuenca }\end{array}$ & $\begin{array}{l}\text { Dos inscripciones, una totalmente destruida y } \\
\text { la otra en parte conservada, recogidas de los } \\
\text { mss. de J. Fernández Franco y A. M. Burriel, } \\
\text { de quien la vio y copió }\end{array}$ \\
\hline 3171 & $69[3]$ & Albarracín (Teruel) & $\begin{array}{l}\text { J. F. A. de Uztarroz, Zaragoza antigua } \\
\text { manuscrita, de quien la vio y copió }\end{array}$ \\
\hline 3172 & $73[4]$ & Colomarde (Teruel) & $\begin{array}{c}\text { J. F. A. de Uztarroz, Zaragoza antigua } \\
\text { manuscrita }\end{array}$ \\
\hline
\end{tabular}




\begin{tabular}{|c|c|c|c|}
\hline CIL II & Folios & Procedencia & Fuente \\
\hline 3177 & $61[1]$ & $\begin{array}{c}\text { Ermita de Ntra. Sra. Señora } \\
\text { del Cid, cerca de La Iglesuela } \\
\text { (Teruel) }\end{array}$ & Mss. de V. J. de Lastanosa \\
\hline 3178 & $71[2]$ & $\begin{array}{c}\text { Ermita de Ntra. Sra. Señora } \\
\text { del Cid, cerca de La Iglesuela } \\
\text { (Teruel) }\end{array}$ & Mss. de V. J. de Lastanosa \\
\hline 3180 Tachada & $62[2]$ & Valera de Arriba (Cuenca) & A. M. Burriel \\
\hline 3183Tachada & $55[2]$ & Valera de Arriba (Cuenca) & A. M. Burriel \\
\hline 3184 Tachada & $55[1]$ & Valera de Arriba (Cuenca) & A. M. Burriel \\
\hline 3185 Tachada & $56[3]$ & Valera de Arriba (Cuenca) & A. M. Burriel \\
\hline 3186 Tachada & $56[3]$ & Valera de Arriba (Cuenca) & A. M. Burriel \\
\hline 3187 Tachada & $57[1]$ & Valera de Arriba (Cuenca) & A. M. Burriel \\
\hline 3188 & $58[3]$ & Valera de Arriba (Cuenca) & A. M. Burriel \\
\hline 3189 Tachada & $60[3]$ & Valera de Arriba (Cuenca) & A. M. Burriel \\
\hline 3193 Tachada & $62[1]$ & Valera de Arriba (Cuenca) & A. M. Burriel \\
\hline 3194 Tachada & $61[4]$ & Valera de Arriba (Cuenca) & A. M. Burriel \\
\hline 3195 Tachada & $62[3]$ & Valera de Arriba (Cuenca) & A. M. Burriel \\
\hline 3196 Tachada & $63[1]$ & Valera de Arriba (Cuenca) & A. M. Burriel \\
\hline 3196 Tachada & $63[1]$ & Valera de Arriba (Cuenca) & A. M. Burriel \\
\hline 3198 Tachada & $69[3]$ & Valera de Arriba (Cuenca) & A. M. Burriel \\
\hline 3199 Tachada & $70[2]$ & Valera de Arriba (Cuenca) & A. M. Burriel \\
\hline 3200 & $52[4]$ & Valera de Arriba (Cuenca) & A. M. Burriel \\
\hline 3201 Tachada & $70[3]$ & Valera de Arriba (Cuenca) & A. M. Burriel \\
\hline 3202 Tachada & $70[3]$ & Valera de Arriba (Cuenca) & A. M. Burriel \\
\hline 3203 Tachada & $68[1]$ & Valera de Arriba (Cuenca) & A. M. Burriel \\
\hline 3204 & $72[2]$ & Valera de Arriba (Cuenca) & A. M. Burriel \\
\hline 3205 Tachada & $73[3]$ & Valera de Arriba (Cuenca) & A. M. Burriel, de quien la vio y copió \\
\hline 3207 Tachada & $74[2]$ & Valera de Arriba (Cuenca) & A. M. Burriel \\
\hline 3208 Tachada & $66[2]$ & Valera de Arriba (Cuenca) & A. M. Burriel \\
\hline 3211 Tachada & $80[3]$ & Valera de Arriba (Cuenca) & A. M. Burriel \\
\hline 3212 & $81[2]$ & Valera de Arriba (Cuenca) & A. M. Burriel \\
\hline 3215 & $43[1]$ & $\begin{array}{c}\text { Gascas (Olmedilla de Alarcón, } \\
\text { Cuenca) }\end{array}$ & A. M. Burriel \\
\hline 3219 & $74[2]$ & Utiel (Valencia) & A. M. Burriel, de quien la vio y la copió \\
\hline 3225 & $65[3]$ & $\begin{array}{c}\text { en la dehesa, que dicen Morillas } \\
\text { de Chiquero junto a Luciana } \\
\text { (Ciudad Real) }\end{array}$ & A. M. Burriel, de quien la vio y copió \\
\hline 3227 & $42[4]$ & Almagro (Ciudad Real) & A. M. Burriel \\
\hline 3228 & $42[1]$ & Fuenllana (Ciudad Real) & A. M. Burriel \\
\hline 3229 & $46[4]$ & Alhambra (Ciudad Real) & A. M. Burriel \\
\hline
\end{tabular}




\begin{tabular}{|c|c|c|c|}
\hline CIL II & Folios & Procedencia & Fuente \\
\hline 3230 & $51[1]$ & Alhambra (Ciudad Real) & A. M. Burriel \\
\hline 3231 & $51[2]$ & Alhambra (Ciudad Real) & A. M. Burriel \\
\hline 3232 & $66[3]$ & $\begin{array}{l}\text { Villanueva de los Infantes } \\
\text { (Ciudad Real) }\end{array}$ & A. M. Burrie, de quien la vio y copió \\
\hline 3335 & $42[4]$ & Baeza (Granada) & L. J. Velázquez \\
\hline 3358 & $40[3]$ & Jaén (Jaén) & L. J. Velázquez \\
\hline 3361 & $77[4]$ & Jaén (Jaén) & L. J. Velázquez \\
\hline 3368 & $56[3]$ & Jaén (Jaén) & L. J. Velázquez \\
\hline 3386 & $42[3]$ & $\begin{array}{l}\text { Sevilla (Sevilla), hallada junto a } \\
\text { Guadix }\end{array}$ & L. J. Velázquez \\
\hline 3386 & $86[3]$ & Sevilla & L. J. Velázquez \\
\hline 3392 & $35[2]$ & Guadix (Granada) & Pastor \\
\hline 3406 & $39[2]$ & $\begin{array}{l}\text { Galera (Granada), traída del sitio } \\
\text { llamado La Cuesta de los Baños }\end{array}$ & De quien lo vio, y copió \\
\hline 3410 & $45[5]$ & Cartagena (Murcia) & $\begin{array}{l}\text { Mss. de F. Jiménez. También recoge la lectura } \\
\text { de los mss. de R. Caro }\end{array}$ \\
\hline 3412 & $35[1]$ & Cartagena (Murcia) & A. M. Burriel \\
\hline 3417 & $29[3]$ & Cartagena (Murcia) & $\begin{array}{c}\text { De quien lo vio, y copió. En nota recoge la } \\
\text { lectura de T. Reinesio }(3, \mathrm{n} .70)\end{array}$ \\
\hline 3418 & $54[2]$ & Cartagena (Murcia) & A. M. Burriel \\
\hline 3421 & $81[1]$ & Cartagena (Murcia) & A. M. Burriel, de quien la vio y copió \\
\hline 3422 & $80[4]$ & Cartagena (Murcia) & A. M. Burriel, de quien la vio y copió \\
\hline $\begin{array}{c}3423 \\
\text { (cfr. 5941- 3424) }\end{array}$ & $34[3]$ & Cartagena (Murcia) & A. M. Burriel \\
\hline 3425 & $77[3]$ & Cartagena (Murcia) & $\begin{array}{l}\text { A. M. Burriel . También la recoge de los mss. } \\
\text { de F. Jiménez }\end{array}$ \\
\hline 3426 & $77[3]$ & Cartagena (Murcia) & A. M. Burriel, de quien la vio y copió \\
\hline 3433 & $80[2]$ & Cartagena (Murcia) & $\begin{array}{l}\text { A. M. Burriel, de quien la vio y copió. } \\
\text { También en el Diario de los Literatos de } \\
\text { España (t. 3, p. 413) }\end{array}$ \\
\hline 3437 & $52[3]$ & Cartagena (Murcia) & A. M. Burriel \\
\hline 3438 & $\begin{array}{l}53[3]- \\
53[4]\end{array}$ & Cartagena (Murcia) & J. Talamanco \\
\hline 3441 & $67[3]$ & Catagena (Murcia) & Mss. de F. Jiménez \\
\hline 3449 & $57[3]$ & Cartagena (Murcia) & A. M. Burriel \\
\hline 3458 & $59[3]$ & Cartagena (Murcia) & J. Talamanco \\
\hline 3464 & $62[4]$ & Cartagena (Murcia) & Mss. de F. Jiménez \\
\hline 3465 & $63[2]$ & Cartagena (Murcia) & J. Talamanco \\
\hline 3466 & $63[3]$ & Cartagena (Murcia) & A. M. Burriel, de quien la vio y copió \\
\hline 3467 & $63[3]$ & Cartagena (Murcia) & A. M. Burriel, de quien la vio y copió \\
\hline 3468 & $63[3]$ & Cartagena (Murcia) & A. M. Burriel, de quien la vio y copió \\
\hline
\end{tabular}




\begin{tabular}{|c|c|c|c|}
\hline CIL II & Folios & Procedencia & Fuente \\
\hline 3469 & $48[3]$ & Cartagena (Murcia) & A. M. Burriel \\
\hline 3469 & $64[1]$ & Cartagena (Murcia) & Mss. de F. Jiménez \\
\hline 3470 & & Cartagena (Murcia) & Mss. de F. Jiménez \\
\hline 3475 & $66[3]$ & Cartagena (Murcia) & A. M. Burriel, de quien la vio y copió \\
\hline 3476 & $66[4]$ & Cartagena (Murcia) & J. Talamanco \\
\hline 3477 & $67[1]$ & Cartagena (Murcia) & Mss. de F. Jiménez \\
\hline 3478 & $67[1]$ & Cartagena (Murcia) & Mss. de F. Jiménez \\
\hline 3482 & $68[1]$ & Cartagena (Murcia) & A. M. Burriel, de quien la vio y copió \\
\hline 3483 & $68[1]$ & Cartagena (Murcia) & A. M. Burriel, de quien la vio y copió \\
\hline 3484 & $68[2]$ & Cartagena (Murcia) & J. Talamanco \\
\hline 3487 & $69[3]$ & Cartagena (Murcia) & Mss. de M. Jimena \\
\hline 3492 & $62[3]$ & Cartagena (Murcia) & Mss. de F. Jiménez \\
\hline 3494 & $69[4]$ & Cartagena (Murcia) & Mss. de F. Jiménez \\
\hline 3498 & $71[1]$ & Cartagena (Murcia) & A. M. Burriel, de quien la vio y copió \\
\hline 3501 & $79[4]$ & Cartagena (Murcia) & Mss. de F. Jiménez \\
\hline 3503 & $60[3]$ & Cartagena (Murcia) & A. M. Burriel, de quien la vio y copió \\
\hline 3504 & $\begin{array}{c}73[2]- \\
73[3]\end{array}$ & Cartagena (Murcia) & A. M. Burriel, de quien la vio y copió \\
\hline 3508 & $53[4]$ & Cartagena (Murcia) & Mss. de F. Jiménez \\
\hline 3510 & $75[2]$ & Cartagena (Murcia) & A. M. Burriel, de quien la vio y copió \\
\hline 3523 & $52[4]$ & Murcia (Murcia) & E. Sauri \\
\hline 3523 & $81[4]$ & Murcia (Murcia) & E. Sauri \\
\hline 3531 & $80[1]$ & Totana (Murcia) & E. Sauri, de quien la vio y copió \\
\hline $3752^{a}$ y 3753 & $72[4]$ & Valencia (Valencia) & A. M. Burriel, de quien la vio y copió \\
\hline 3990 & $74[2]$ & Jerica (Castellón de la Plana) & Copia ms. de letra de Pedro Juan Núñez \\
\hline 3997 & $77[1]$ & Jérica (Castellón de la Plana) & $\begin{array}{l}\text { Copia ms. de letra de Pedro Juan Núñez, } \\
\text { también recoge la inscripción con diferente } \\
\text { lectura F. Diago, Anales del Reino de Valencia }\end{array}$ \\
\hline 4054 & $29[1]$ & Tortosa (Tarragona) & F. Pérez Bayer \\
\hline 4058 & $37[3]$ & Tortosa (Tarragona) & F. Pérez Bayer \\
\hline 4061 & $53[4]$ & Tortosa (Tarragona) & F. Pérez Bayer \\
\hline 4062 & $54[2]$ & Tortosa (Tarragona) & F. Pérez Bayer \\
\hline 4064 & $53[2]$ & Tortosa (Tarragona) & F. Pérez Bayer \\
\hline 4067 & $72[2]$ & Tortosa (Tarragona) & $\begin{array}{l}\text { J. F. A. de Uztarroz, Zaragoza antigua } \\
\text { manuscrita, de quien la vio y copió }\end{array}$ \\
\hline 4073 & $42[2]$ & $\begin{array}{c}\text { Zaragoza (Zaragoza), procede de } \\
\text { Tarragona, actualmente en dicha } \\
\text { ciudad. }\end{array}$ & $\begin{array}{c}\text { J. F. A. de Uztarroz, la toma del padre Paulo } \\
\text { de Rajas }\end{array}$ \\
\hline 4090 & $45[3]$ & Tarragona (Tarragona) & F. Pérez Bayer \\
\hline
\end{tabular}




\begin{tabular}{|c|c|c|c|}
\hline CIL II & Folios & Procedencia & Fuente \\
\hline 4203 & $47[3]$ & $\begin{array}{l}\text { Sevilla (Sevilla) copia moderna, } \\
\text { sacada de la original que está en } \\
\text { Tarragona }\end{array}$ & $\begin{array}{l}\text { L. J. Velázquez, publicada por J. Gruter, de } \\
\text { A. Schott }\end{array}$ \\
\hline 4241 & $79[1]$ & Tarragona (Tarragona) & $\begin{array}{l}\text { J. F. A. de Uztarroz, Zaragoza antigua } \\
\text { manuscrita, de una copia de J. Zurita, } \\
\text { procede de un libro de inscripciones que tenía } \\
\text { el Conde de Guimerá. }\end{array}$ \\
\hline 4246 & $\begin{array}{l}53[2]- \\
53[3]\end{array}$ & $\begin{array}{c}\text { Sevilla (Sevilla) en casa del } \\
\text { Duque de Alcalá, copia moderna } \\
\text { sacada de la original que está en } \\
\text { Tarragona }\end{array}$ & $\begin{array}{l}\text { L. J. Velázquez, recogida por A. de Morales, } \\
\text { J. Gruter, C. Clusio y mss. de A. Schott }\end{array}$ \\
\hline 4251 & $32[2]$ & $\begin{array}{l}\text { Sevilla (Sevilla), copia moderna } \\
\text { que se conserva en la Casa de los } \\
\text { Duques de Alcalá, sacada de la } \\
\text { original que está en Tarragona. }\end{array}$ & $\begin{array}{l}\text { L. J. Velázquez. También la recoge J. Gruter } \\
\text { (p. 481, 1), A. Schott, mss de R. Caro y J. } \\
\text { Scaliguer. }\end{array}$ \\
\hline 4649 & $37[2]$ & $\begin{array}{l}\text { Camino de la Plata, camino de } \\
\text { Cáceres a Mérida. }\end{array}$ & L. Rodríguez \\
\hline 4651 & $30[1]$ & $\begin{array}{l}\text { Ventas del Alcona, calzada } \\
\text { romana, camino de la plata. }\end{array}$ & L. J. Velázquez \\
\hline 4658 & $34[1]$ & Carcaboso (Cáceres) & L. Rodríguez \\
\hline 4659 & 34 [1] & Carcaboso (Cáceres) & L. Rodríguez \\
\hline 4660 & $37[1]$ & Carcaboso (Cáceres) & L. Rodríguez \\
\hline 4662 & $34[2]$ & $\begin{array}{l}\text { Oliva, llevada de Caparra } \\
\text { (Cáceres) }\end{array}$ & L. J. Velázquez \\
\hline 4666 & $81[2]$ & $\begin{array}{l}\text { Oliva, junto a Plasencia, llevada } \\
\text { de la aldea de Caparra (Cáceres) }\end{array}$ & L. J. Velázquez \\
\hline 4677 & $32[4]$ & $\begin{array}{l}\text { La Calzada. Camino de la Plata } \\
\text { (hacia Salamanca) }\end{array}$ & L. J. Velázquez \\
\hline 4678 & $34[2]$ & $\begin{array}{l}\text { La Calzada. Camino de la Plata } \\
\text { (hacia Salamanca) }\end{array}$ & L. J. Velázquez \\
\hline 4679 & $33[4]$ & $\begin{array}{l}\text { La Calzada. Camino de la Plata } \\
\text { (hacia Salamanca) }\end{array}$ & L. J. Velázquez \\
\hline 4680 & $32[4]$ & $\begin{array}{l}\text { La Calzada. Camino de la Plata } \\
\text { (hacia Salamanca) }\end{array}$ & L. J. Velázquez \\
\hline 4683 & $31[3]$ & $\begin{array}{l}\text { En el Camino de la Plata, cuarto } \\
\text { de legua de la Venta de Siete } \\
\text { Carreras, hacia el mediodía en el } \\
\text { camino que va desde allí a Mérida. }\end{array}$ & L. J. Velázquez \\
\hline 4689 & $36[4]$ & Málaga (Málaga) & L. J. Velázquez \\
\hline 4699 & $36[3]$ & Montoro (Córdoba) & T. A. de Gusseme \\
\hline 4701 & $28[3]$ & Córdoba & L. J. Velázquez \\
\hline 4703 & $28[4]$ & Córdoba & L. J. Velázquez \\
\hline 4705 & $28[4]$ & $\begin{array}{l}\text { Sitio de la Cuesta del } \\
\text { Espino(Córdoba) }\end{array}$ & L. J. Velázquez \\
\hline
\end{tabular}




\begin{tabular}{|c|c|c|c|}
\hline CIL II & Folios & Procedencia & Fuente \\
\hline 4712 & $30[2]$ & Córdoba & L. J. Velázquez \\
\hline 4715 & $30[2]$ & Córdoba & L. J. Velázquez \\
\hline 4716 & $30[4]$ & Córdoba & $\begin{array}{l}\text { L. J. Velázquez. También la recoge Ribas, } \\
\text { Antigüedades de Córdoba, p. } 55 .\end{array}$ \\
\hline 4717 & $30[4]$ & Córdoba & L. J. Velázquez \\
\hline 4718 & $31[1]$ & Córdoba & L. J. Velázquez \\
\hline 4719 & $31[3]$ & Córdoba & $\begin{array}{c}\text { L. J. Velázquez. La inscripción se conserva en } \\
\text { la casa de Pedro de Villaceballos }\end{array}$ \\
\hline $4728^{\mathrm{a}}$ & $39[2]$ & Córdoba (Córdoba) & \begin{tabular}{|c|} 
L. J. Velázquez \\
\end{tabular} \\
\hline 4733 & $39[1]$ & Córdoba (Córdoba) & L. J. Velázquez \\
\hline 4734 & $31[3]$ & Puerto de Santa María (Cádiz) & De quien lo vio, y copió \\
\hline 4877 & $34[3]$ & Almuiña (Pontevedra) & M. Sarmiento \\
\hline 4883 Tachada & $29[4]$ & Herrera de Pisuerga (Palencia) & Tachado \\
\hline 4884 Tachada & $31[2]$ & Herrera de Pisiuerga (Palencia) & Tachado \\
\hline 4931 & $28[3]$ & La Guardia (Jaén) & L. J. Velázquez \\
\hline 4936 & $28[2]$ & Totana (Murcia) & E. Saurin \\
\hline 4937 & $\begin{array}{l}28[2]- \\
28[3]\end{array}$ & Lorca (Murcia) & Sánchez Rubio \\
\hline $4962,{ }_{2}$ & $104[3]$ & Sevilla & L. J. Velázquez \\
\hline $4968,_{8}$ & $104[4]$ & Las Mezquitillas (Sevilla) & T. A. Gusseme \\
\hline $4976,{ }_{4}$ & $104[1]$ & Zaragoza & J. F. A. de Uztarroz \\
\hline 4982 & $63[2]$ & Sevilla (Sevilla) & Mss. de R. Caro \\
\hline $\begin{array}{c}5941 \\
\text { (cfr. } 3423-3424)\end{array}$ & $34[4]$ & Caravaca (Murcia) & $\begin{array}{l}\text { P. E. Ortega. También la recoge L. A. } \\
\text { Muratori (p. 1096, 1) y éste de los mss. } \\
\text { farnesianos }\end{array}$ \\
\hline 5961 & $79[2]$ & Denia (Alicante) & F. Pérez Bayer \\
\hline $\begin{array}{l}\text { Almagro-Gor- } \\
\text { bea, M., 2003, } \\
\text { F134A-B, p. } 342\end{array}$ & $40[1]$ & Trujillo (Cáceres) & Mss. de P. Valera \\
\hline $\begin{array}{l}\text { Almagro-Gor- } \\
\text { bea, M., 2003, } \\
\text { F154A-C, p. } \\
\text { 354-355 }\end{array}$ & $40[1]$ & Incierta provincia de Galicia & Mss. de P. Valera \\
\hline $\begin{array}{l}\text { Almagro-Gorbea, } \\
\text { M., } 2003, \text { F22A-E, } \\
\text { p. } 254-255\end{array}$ & $39[4]$ & Algeciras (Cádiz) & Mss. de P. Valera \\
\hline $\begin{array}{l}\text { Almagro-Gorbea, } \\
\text { M., } 2003, \text { F25A-C, } \\
\text { p. } 257-258\end{array}$ & $39[3]$ & $\begin{array}{c}\text { Valle de Aldalajís (Granada), en } \\
\text { el Gabinete de M. E. Trabuco } \\
\text { (Málaga) }\end{array}$ & L. J. Velázquez. \\
\hline $\begin{array}{l}\text { Almagro-Gorbea, } \\
\text { M., } 2003, \text { F27A-F, } \\
\text { p. } 259-260\end{array}$ & $39[4]$ & $\begin{array}{c}\text { Málaga (Málaga), en casa del } \\
\text { duque de Alcalá }\end{array}$ & Mss. de P. Valera \\
\hline
\end{tabular}




\begin{tabular}{|c|c|c|c|}
\hline CIL II & Folios & Procedencia & Fuente \\
\hline $\begin{array}{l}\text { Almagro-Gorbea, } \\
\text { M., } 2003 \text {, F28A-N, } \\
\text { p. } 260-266 \text { CIL II, } \\
\text { p. } 251 .\end{array}$ & $39[3]$ & Málaga (Málaga) & Mss. de P. Valera y B. Aldrete \\
\hline $\begin{array}{l}\text { Almagro-Gorbea, } \\
\text { M., 2003, F-40A- } \\
\text { C, p. 280-281 }\end{array}$ & $39[4]$ & Granada (Granada) & L. J. Velázquez \\
\hline $\begin{array}{l}\text { Almagro-Gorbea, } \\
\text { M., } 2003, \text { F44A-C, } \\
\text { p. } 285\end{array}$ & $41[1]$ & Granada (Granada) & De quien lo vio, y copió \\
\hline $\begin{array}{l}\text { Almagro-Gorbea, } \\
\text { M., 2003, F7A-F, } \\
\text { p. 244-246 }\end{array}$ & $39[4]$ & $\begin{array}{c}\text { Córdoba (Córdoba), llevada de } \\
\text { Carmona (Sevilla) }\end{array}$ & L. J. Velázquez, \\
\hline $\begin{array}{l}\text { Almagro-Gorbea, } \\
\text { Mi., 2003, F-91A-C, } \\
\text { p. 315-316. }\end{array}$ & $25[2]$ & $\begin{array}{c}\text { En la Ermita de Ntra. Sra. } \\
\text { del Cid, cerca de la Iglesuela } \\
\text { (Teruel) }\end{array}$ & Mss. de P. Valera \\
\hline $\begin{array}{l}\text { Almagro-Gorbea, } \\
\text { M., 2003, p.415 }\end{array}$ & $\begin{array}{c}41[2] \\
\text { y } 87 \\
{[1]}\end{array}$ & $\begin{array}{l}\text { Lorilla (Sevilla), en casa del } \\
\text { Marqués de Estepa }\end{array}$ & Mss. de P. Valera \\
\hline $\begin{array}{l}\text { Almagro-Gorbea, } \\
\text { M., 2003, p.415 }\end{array}$ & $44[2]$ & Tui (Pontevedra) & Mss. de P. Valera \\
\hline EgipciaSin texto & $40[2]$ & $\begin{array}{l}\text { Madrid (Madrid), en el Real } \\
\text { Gabinete de Historia Natural }\end{array}$ & L. J. Velázquez \\
\hline $\begin{array}{l}\text { Flores de Oddouz, Jii, } \\
\text { lám. XLVIII y XLVII }\end{array}$ & $\begin{array}{c}26[1] \\
-26 \\
{[3]} \\
\end{array}$ & Granada & $\begin{array}{l}\text { L. J. Velázquez, textos también en notas } 20 \\
\text { y } 21 .\end{array}$ \\
\hline $\begin{array}{l}\text { Flores de Oddouz, } \\
\text { J., lám. LIV }\end{array}$ & $26[3]$ & Granada & L. J. Velázquez \\
\hline $\begin{array}{l}\text { Flores de Oddouz, } \\
\text { J., lám. LXI }\end{array}$ & $28[1]$ & Granada & L. J. Velázquez \\
\hline $\begin{array}{l}\text { Flores de Oddouz, } \\
\text { J., lám. LXXII. }\end{array}$ & $40[4]$ & Granada (Granada) & L. J. Velázquez \\
\hline $\begin{array}{l}\text { Flores de Oddouz, } \\
\text { J., lám. LXXIV. }\end{array}$ & $29[1]$ & Granada & De quien lo vio, y copió \\
\hline Griega & $25[2]$ & Cazlona (Jaén) & Mss. de P. Valera \\
\hline II2/14, 0006 & $42[4]$ & Valencia (Valencia) & A. M. Burriel \\
\hline II $2 / 5,0003$ & $45[4]$ & La Guardia (Jaén) & L. J. Velázquez \\
\hline II $2 / 5,0004$ & $31[1]$ & La Guardia (Jaén) & L. J. Velázquez \\
\hline II $2 / 5,0004^{*}$ & $81[4]$ & Martos (Jaén) & L. J. Velázquez \\
\hline II $2 / 5,0014$ & $64[1]$ & La Guardia (Jaén) & L. J. Velázquez \\
\hline II $2 / 5,0026$ & $41[1]$ & Jaén (Jaén) & L. J. Velázquez \\
\hline II $2 / 5,0029$ & $62[1]$ & Jaén (Jaén) & L. J. Velázquez \\
\hline II $2 / 5,0032$ & $62[2]$ & Jaén (Jaén) & L. J. Velázquez \\
\hline
\end{tabular}




\begin{tabular}{|c|c|c|c|}
\hline CIL II & Folios & Procedencia & Fuente \\
\hline $\begin{array}{l}\text { II } 2 / 5,0032 * \\
\quad-0033^{*}\end{array}$ & $\begin{array}{l}25[4]- \\
26[1]\end{array}$ & Granada & L. J. Velázquez \\
\hline II $2 / 5,0038^{*}$ & $28[2]$ & Granada & L. J. Velázquez \\
\hline II $2 / 5,0039^{*}$ & $40[3]$ & Granada (Granada) & Mss. de P. Valera \\
\hline II $2 / 5,0044$ & $63[3]$ & Jaén (Jaén) & L. J. Velázquez \\
\hline II $2 / 5,0046^{*}$ & $32[1]$ & Antequera (Málaga) & $\begin{array}{c}\text { L. J. Velázquez. También la recoge L. A. } \\
\text { Muratori (p. 1797, 2) }\end{array}$ \\
\hline II $2 / 5,0047 *$ & $36[1]$ & Antequera (Málaga) & L. J. Velázquez \\
\hline II $2 / 5,0049 *$ & $31[2]$ & $\begin{array}{l}\text { Antequera (Málaga), llevada de } \\
\text { las ruinas de Nescania }\end{array}$ & $\begin{array}{l}\text { Mss. F. de Cabrera, Historia de Antequera } \\
\text { manuscrita }\end{array}$ \\
\hline II $2 / 5,0065$ & $29[4]$ & Martos & L. J. Velázquez \\
\hline $\begin{array}{l}\text { II } 2 / 5,0065 \\
\text { Tachada }\end{array}$ & $42[3]$ & Martos (Jaén) & L. J. Velázquez \\
\hline II $2 / 5,0069$ & $44[4]$ & Martos (Jaén) & L. J. Velázquez \\
\hline II $2 / 5,0072$ & $29[1]$ & Martos (Jaén) & $\begin{array}{l}\text { Mss. de D. de Villalta, M. Jimena,J. } \\
\text { Fernández Franco y E. B. de Alfaro }\end{array}$ \\
\hline II $2 / 5,0074$ & $36[1]$ & Martos (Jaén) & L. J. Velázquez \\
\hline $\begin{array}{l}\text { II } 2 / 5,0075 ; \mathrm{cfr} . \\
\text { II } 2 / 5,76\end{array}$ & $36[2]$ & Martos (Jaén) & L. J. Velázquez \\
\hline II $2 / 5,0077$ & $36[3]$ & Martos (Jaén) & L. J. Velázquez \\
\hline II $2 / 5,0078$ & $36[1]$ & Martos (Jaén) & L. J. Velázquez \\
\hline II $2 / 5,0079$ & $38[1]$ & Martos (Córdoba) & A. M. Burriel \\
\hline II $2 / 5,0081$ & $56[2]$ & $\begin{array}{c}\text { Martos (Jaén), llevada de la villa } \\
\text { de Torre Jimeno }\end{array}$ & L. J. Velázquez \\
\hline II $2 / 5,0086$ & $60[2]$ & Martos (Jaén) & L. J. Velázquez \\
\hline II $2 / 5,0090$ & $51[1]$ & Martos (Jaén) & L. J. Velázquez \\
\hline $\begin{array}{l}\text { II } 2 / 5,0091, \text { cf. } 5 \\
0150\end{array}$ & $52[2]$ & Martos (Jaén) & L. J. Velázquez \\
\hline II $2 / 5,0093$ & $77[2]$ & Martos (Jaén) & L. J. Velázquez \\
\hline II $2 / 5,0094$ & $70[1]$ & Martos (Jaén) & L. J. Velázquez \\
\hline II $2 / 5,0096$ & $46[4]$ & Martos (Jaén) & L. J. Velázquez \\
\hline II $2 / 5,0098$ & $51[3]$ & Martos (Jaén) & L. J. Velázquez \\
\hline II $2 / 5,0102$ & $58[1]$ & Martos (Jaén) & L. J. Velázquez \\
\hline II $2 / 5,0114$ & $63[2]$ & Martos (Jaén) & $\begin{array}{l}\text { Mss. de D. de Villalta, F. Jiménez, J. } \\
\text { Fernández Franco y E. B. de Alfaro }\end{array}$ \\
\hline II $2 / 5,0119$ & $65[2]$ & Martos (Jaén) & L. J. Velázquez \\
\hline II2/5, 0158Tachada & $50[3]$ & Martos (Jaén) & $\begin{array}{l}\text { Mss. de D. de Villalta, M. Jimena, J. } \\
\text { Fernández Franco y E. B. de Alfaro }\end{array}$ \\
\hline II $2 / 5,0158$ & $66[2]$ & Martos (Jaén) & $\begin{array}{l}\text { Mss. de M. Jimena, D. De Villalta, J. } \\
\text { Fernández Franco y E. B. de Alfaro }\end{array}$ \\
\hline II $2 / 5,0199$ & $46[2]$ & Martos (Jaén) & L. J. Velázquez \\
\hline
\end{tabular}




\begin{tabular}{|c|c|c|c|}
\hline CIL II & Folios & Procedencia & Fuente \\
\hline II $2 / 5,0270$ & $62[1]$ & Luque (Córdoba) & Mss. de E. B. de Alfaro \\
\hline II $2 / 5,0296$ & $\begin{array}{l}53[4]- \\
54[1]\end{array}$ & $\begin{array}{c}\text { Lucena (Córdoba) llevada del } \\
\text { despoblado que dicen la Torre de } \\
\text { Zambra }\end{array}$ & De quien la vio, y copió \\
\hline II $2 / 5,0311$ & $49[2]$ & Cabra (Córdoba) & Mss. de J. Fernández Franco \\
\hline II $2 / 5,0317$ & $57[1]$ & Cabra (Córdoba) & Mss. de J. Fernández Franco \\
\hline II $2 / 5,0321$ & $62[1]$ & $\begin{array}{c}\text { Córdoba (Córdoba), llevada de } \\
\text { Cabra }\end{array}$ & L. J. Velázquez \\
\hline II $2 / 5,0349$ & $59[4]$ & $\begin{array}{c}\text { Córdoba (Córdoba), llevada de } \\
\text { un sitio llamado Torre del Puerto } \\
\text { a dos leguas de Castro del Río } \\
\text { (Córdoba) }\end{array}$ & L. J. Velázquez \\
\hline II $2 / 5,0369$ & $29[1]$ & Baena (Córdoba) & Mss. de E. B. de Alfaro \\
\hline II2/5, 0387 & $50[4]$ & Castro del Río (Córdoba) & P. Villaceballos \\
\hline II2/5, 0398 & $68[2]$ & $\begin{array}{c}\text { Córdoba (Córdoba), llevada de } \\
\text { la villa de Castro del Río }\end{array}$ & L. J. Velázquez \\
\hline II $2 / 5,0440$ & $30[2]$ & Espejo (Córdoba) & Mss. de J. Fernández Franco \\
\hline II $2 / 5,0442$ & $37[1]$ & Espejo (Córdoba) & Mss. de J. Fernández Franco \\
\hline II $2 / 5,0448$ & $81[2]$ & Espejo (Córdoba) & Mss. de J. Fernández Franco \\
\hline II $2 / 5,0450$ & $52[3]$ & Espejo (Córdoba) & Mss. de J. Fernández Franco \\
\hline II $2 / 5,0476$ & $60[4]$ & $\begin{array}{c}\text { Despoblado de Teba La Vieja a } \\
\text { cuatro leguas al mediodía de la } \\
\text { ciudad de Córdoba, en el camino } \\
\text { a la villa de Castro del Río }\end{array}$ & Mss. de E. B. de Alfaro \\
\hline II $2 / 5,0486$ & $29[1]$ & Montemayor (Córdoba) & J. Vázquez \\
\hline II $2 / 5,0487$ & $47[1]$ & Espejo (Córdoba) & Mss. de J. Fernández Franco \\
\hline II $2 / 5,0488$ & $29[2]$ & Montemayor (Córdoba) & Mss. de J. Fernández Franco \\
\hline II $2 / 5,0489$ & $29[2]$ & Montemayor (Córdoba) & Mss. de J. Fernández Franco \\
\hline II $2 / 5,0502$ & $56[4]$ & Montilla (Córdoba) & E. Trabuco \\
\hline II $2 / 5,0504$ & $62[4]$ & Montemayor (Córdoba) & J. Vázquez, de quien la vio y copió \\
\hline II $2 / 5,0530$ & $60[1]$ & Córdoba (Córdoba) & L. J. Velázquez \\
\hline II $2 / 5,0562$ & $62[4]$ & Montilla (Córdoba) & E. Trabuco, de quien la vio y copió \\
\hline II2/5, 0563 & $62[3]$ & Montilla (Córdoba) & L. J. Velázquez \\
\hline II $2 / 5,0619$ & $41[4]$ & Granada (Granada) & L. J. Velázquez \\
\hline II $2 / 5,0620$ & $37[2]$ & Granada (Granada) & L. J. Velázquez \\
\hline II $2 / 5,0629$ & $48[2]$ & Granada (Granada) & L. J. Velázquez \\
\hline II $2 / 5,0632$ & $80[3]$ & Granada (Granada) & L. J. Velázquez \\
\hline II $2 / 5,0633$ & $77[2]$ & Granada (Granada) & L. J. Velázquez \\
\hline II $2 / 5,0637$ & $60[2]$ & Granada (Granada) & L. J. Velázquez \\
\hline II $2 / 5,0638$ & $51[3]$ & Granada (Granada) & L. J. Velázquez \\
\hline II $2 / 5,0677$ & $30[1]$ & Cerca de Lora del Río (Sevilla) & Mss. de P. Valera \\
\hline
\end{tabular}




\begin{tabular}{|c|c|c|c|}
\hline CIL II & Folios & Procedencia & Fuente \\
\hline II $2 / 5,0677$ & $30[1]$ & Pinos Puente (Granada) & $\begin{array}{l}\text { L. J. Velázquez. También la toma de J. Gruter } \\
\text { (p. 235, 10) y éste de O. Panvinio. Añade en } \\
\text { nota la lectura que trae Antonio Agustín y A. } \\
\text { Occon (p. 15, 2) }\end{array}$ \\
\hline II $2 / 5,0681$ & $48[4]$ & Granada (Granada) & $\begin{array}{l}\text { L. J. Velázquez. También la toma de L. A. } \\
\text { Muratori y éste de los mss. farnesianos que la } \\
\text { ubican en Pinos Puente }\end{array}$ \\
\hline II $2 / 5,0684$ & $81[3]$ & Illora (Granada) & Mss. de J. Fernández Franco \\
\hline II $2 / 5,0689$ & $75[1]$ & Pinos de la Puente (Granada) & L. J. Velázquez \\
\hline II $2 / 5,0730$ & $33[4]$ & $\begin{array}{l}\text { Villanueva de Cauche } \\
\text { (Antequera, Málaga) }\end{array}$ & L. J. Velázquez \\
\hline II $2 / 5,0731$ & $34[1]$ & $\begin{array}{l}\text { Villanueva de Cauche } \\
\text { (Antequera, Málaga) }\end{array}$ & L. J. Velázquez \\
\hline II $2 / 5,0733$ & $49[3]$ & $\begin{array}{l}\text { Villanueva de Cauche } \\
\text { (Antequera, Málaga) }\end{array}$ & L. J. Velázquez \\
\hline II $2 / 5,0734$ & $66[3]$ & Villanueva de Cauche & L. J. Velázquez \\
\hline II $2 / 5,0736$ & $50[4]$ & $\begin{array}{l}\text { Cerro León, inmediata a la que } \\
\text { llaman Huerta de la Solana, dos } \\
\text { leguas de Antequera (Málaga) }\end{array}$ & L. J. Velázquez \\
\hline II $2 / 5,0739$ & $72[3]$ & Antequera (Málaga) & L. J. Velázquez \\
\hline II $2 / 5,0742$ & $41[4]$ & Antequera (Málaga) & L. J. Velázquez \\
\hline II $2 / 5,0743$ & $42[3]$ & Antequera (Málaga) & $\begin{array}{l}\text { Mss. de P. Valera. L. A. Muratori la publicó } \\
\text { incompleta, copiada de los mss. farnesianos }\end{array}$ \\
\hline II2/5, 0745 & $39[2]$ & Antequera (Málaga) & L. J. Velázquez \\
\hline II $2 / 5,0748$ & $29[3]$ & Antequera (Málaga) & $\begin{array}{l}\text { L. J. Velázquez. También la recoge A. X. } \\
\text { Panel (p. 161) }\end{array}$ \\
\hline II2/5, 0749 & $30[3]$ & Antequera (Málaga) & M. Ruiz \\
\hline II $2 / 5,0750$ & $30[4]$ & Antequera (Málaga) & L. J. Velázquez \\
\hline II $2 / 5,0753$ & $81[3]$ & Antequera (Málaga) & M. Ruiz \\
\hline II $2 / 5,0754$ & $47[4]$ & $\begin{array}{l}\text { Antequera (Málaga) llevada de } \\
\text { las ruinas de Nescania }\end{array}$ & L. J. Velázquez \\
\hline II $2 / 5,0755$ & $49[4]$ & Antequera (Málaga) & L. J. Velázquez \\
\hline II $2 / 5,0756$ & $53[2]$ & Antequera (Málaga) & L. J. Velázquez \\
\hline II $2 / 5,0757$ & $53[2]$ & Antequera (Málaga) & L. J. Velázquez \\
\hline II $2 / 5,0758$ & $53[2]$ & Antequera (Málaga) & L. J. Velázquez \\
\hline II2/5, 0761 & $70[2]$ & Antequera (Málaga) & L. J. Velázquez \\
\hline II2/5, 0771 & $43[3]$ & Antequera (Málaga) & L. J. Velázquez \\
\hline II $2 / 5,0773$ & $44[1]$ & Antequera (Málaga) & L. J. Velázquez \\
\hline II $2 / 5,0775$ & $34[2]$ & $\begin{array}{c}\text { Antequera (Málaga), llevada de } \\
\text { la antigua Singilia }\end{array}$ & L. J. Velázquez \\
\hline II $2 / 5,0780$ & $51[3]$ & Antequera (Málaga) & L. J. Velázquez \\
\hline II $2 / 5,0783$ & $49[4]$ & Antequera (Málaga) & L. J. Velázquez \\
\hline
\end{tabular}




\begin{tabular}{|c|c|c|c|}
\hline CIL II & Folios & Procedencia & Fuente \\
\hline II $2 / 5,0784$ & $46[1]$ & $\begin{array}{c}\text { Antequera (Málaga), traída de la } \\
\text { antigua Singilia. }\end{array}$ & L. J. Velázquez \\
\hline II $2 / 5,0787$ & $52[2]$ & Antequera (Málaga) & M. Ruiz \\
\hline II $2 / 5,0788$ & $52[2]$ & $\begin{array}{l}\text { Antequera (Málaga), llevada de } \\
\text { las ruinas de la antigua Singilia. }\end{array}$ & L. J. Velázquez \\
\hline II $2 / 5,0792$ & $53[3]$ & $\begin{array}{l}\text { Antequera (Málaga), llevada de } \\
\text { las ruinas de la antigua Singilia. }\end{array}$ & M. Ruiz \\
\hline II $2 / 5,0795$ & $46[2]$ & $\begin{array}{c}\text { Antequera (Málaga), traída de la } \\
\text { antigua Singilia. }\end{array}$ & L. J. Velázquez \\
\hline II $2 / 5,0796$ & $46[2]$ & $\begin{array}{c}\text { Antequera (Málaga), traída de la } \\
\text { antigua Singilia. }\end{array}$ & L. J. Velázquez \\
\hline II $2 / 5,0798$ & $60[1]$ & $\begin{array}{l}\text { Antequera (Málaga), llevada de } \\
\text { las ruinas de la antigua Singilia }\end{array}$ & L. J. Velázquez \\
\hline II $2 / 5,0802$ & $46[1]$ & $\begin{array}{c}\text { Antequera (Málaga), traída de la } \\
\text { antigua Singilia. }\end{array}$ & L. J. Velázquez \\
\hline II $2 / 5,0803$ & $46[2]$ & $\begin{array}{c}\text { Antequera (Málaga), traída de la } \\
\text { antigua Singilia. }\end{array}$ & L. J. Velázquez \\
\hline II $2 / 5,0805$ & $72[1]$ & Antequera (Málaga) & L. J. Velázquez \\
\hline II $2 / 5,0835$ & $42[3]$ & Antequera (Málaga) & F. de Cabrera, Historia de Antequera \\
\hline II $2 / 5,0838$ & $41[4]$ & Antequera (Málaga) & $\begin{array}{l}\text { L. J. Velázquez. También la recoge de J. } \\
\text { Gruter, y éste de Antonio Agustín }\end{array}$ \\
\hline II $2 / 5,0845$ & $31[4]$ & Antequera (Málaga) & L. J. Velázquez \\
\hline II $2 / 5,0846$ & $33[3]$ & $\begin{array}{c}\text { Valle de Abdalajís } \\
\text { (Málaga), llevada de las ruinas de } \\
\text { Nescania }\end{array}$ & L. J. Velázquez \\
\hline II $2 / 5,0847$ & $52[1]$ & $\begin{array}{l}\text { Antequera (Málaga) llevada de } \\
\text { las ruinas de la antigua Nescania }\end{array}$ & L. J. Velázquez \\
\hline II $2 / 5,0848$ & $47[3]$ & $\begin{array}{l}\text { Antequera (Málaga) llevada de } \\
\text { las ruinas de Nescania }\end{array}$ & L. J. Velázquez \\
\hline II $2 / 5,0851-0852$ & $72[3]$ & Antequera (Málaga) & L. J. Velázquez \\
\hline II $2 / 5,0864$ & $62[3]$ & Teba (Málaga) & L. J. Velázquez \\
\hline $\mathrm{II} 2 / 5,0910$ & $41[2]$ & $\begin{array}{c}\text { La Alameda, lugar del Reino de } \\
\text { Sevilla }\end{array}$ & De quien lo vio, y copió. \\
\hline II $2 / 5,0913$ & $52[1]$ & La Alameda (Sevilla) & Mss. de J. Fernández Franco \\
\hline II $2 / 5,0915$ & $\begin{array}{r}52[1]- \\
52[2] \\
\end{array}$ & $\begin{array}{l}\text { Lorilla (Sevilla), llevada de la } \\
\text { aldea de la Alameda }\end{array}$ & De quien la vio, y copió \\
\hline II $2 / 5,0916$ & $\begin{array}{r}65[4]- \\
66[1] \\
\end{array}$ & $\begin{array}{c}\text { Lorilla, junto a la ciudad de } \\
\text { Antequera, llevada de la Alameda }\end{array}$ & de quien la vio y copió \\
\hline II $2 / 5,0920$ & $61[3]$ & $\begin{array}{l}\text { Casaliche, llevada de un sitio } \\
\text { llamado Vado García }\end{array}$ & L. J. Velázquez \\
\hline II $2 / 5,0939$ & $48[1]$ & $\begin{array}{c}\text { Lorilla (Sevilla) llevada de la } \\
\text { villa de Estepa }\end{array}$ & De quien la vio, y copió \\
\hline
\end{tabular}




\begin{tabular}{|c|c|c|c|}
\hline CIL II & Folios & Procedencia & Fuente \\
\hline II $2 / 5,0950$ & $79[3]$ & Lorilla (Sevilla) & L. J. Velázquez \\
\hline II $2 / 5,0960$ & $45[2]$ & Lorilla (Sevilla) & De quien la vio, y copió \\
\hline II $2 / 5,0962$ & $31[2]$ & Cartaza (Málaga) & L. J. Velázquez \\
\hline II $2 / 5,0972$ & $64[4]$ & $\begin{array}{c}\text { Lorilla (Sevilla), junto a } \\
\text { Antequera, llevada de la villa de } \\
\text { Estepa }\end{array}$ & De quien la vio y copió \\
\hline II $2 / 5,0974$ & $67[2]$ & $\begin{array}{c}\text { Lorilla (Sevilla), junto a } \\
\text { Antequera, llevada de la villa de } \\
\text { Estepa }\end{array}$ & L. J. Velázquez \\
\hline II $2 / 5,0985$ & $80[4]$ & $\begin{array}{c}\text { Estepa (Sevilla), llevada del } \\
\text { despoblado de Estepa la Vieja }\end{array}$ & Mss. de J. Fernández Franco \\
\hline II $2 / 5,0990$ & $58[4]$ & $\begin{array}{c}\text { Lorilla, junto a la ciudad de } \\
\text { Antequera, llevada de la Aldea de } \\
\text { Herrera (Sevilla) }\end{array}$ & De quien la vio y copió \\
\hline II $2 / 5,1055$ & $66[2]$ & Osuna (Sevilla) & Mss. de J. Fernández Franco \\
\hline $\mathrm{II} 2 / 5,1140$ & $72[2]$ & $\begin{array}{c}\text { Osuna (Sevilla), llevada del } \\
\text { despoblado que dicen Alcalá a } \\
\text { media legua de la ciudad }\end{array}$ & De quien la vio y copió \\
\hline $\mathrm{II} 2 / 5,1160$ & $61[2]$ & $\begin{array}{l}\text { Córdoba (Córdoba), llevada de } \\
\text { cerca de Écija. Actualmente está } \\
\text { en Écija (Sevilla). }\end{array}$ & L. J. Velázquez \\
\hline $\mathrm{II} 2 / 5,1278$ & $70[1]$ & $\begin{array}{c}\text { Córdoba (Córdoba), llevada de } \\
\text { cerca de Montilla }\end{array}$ & L. J. Velázquez \\
\hline II $2 / 5,1318$ & $73[2]$ & $\begin{array}{c}\text { Córdoba, actualmente en el } \\
\text { Cortijo de la Vega, Palma del Río } \\
\text { (Córdoba) }\end{array}$ & L. J. Velázquez \\
\hline II $2 / 7,0006^{*}$ & $75[2]$ & $\begin{array}{l}\text { Villanueva de Andujar (Jaén), } \\
\text { llevada de las ruinas de la } \\
\text { antigua Iliturgi }\end{array}$ & Mss. de F. Rus Puerta \\
\hline II $2 / 7,0014^{*}$ & $44[2]$ & Porcuna (Jaén) & Mss. de P. Valera \\
\hline $\mathrm{II} 2 / 7,0034$ & $\begin{array}{l}72[3]- \\
72[4]\end{array}$ & $\begin{array}{l}\text { Mengibar (Jaén) llevado desde } \\
\text { un despoblado inmediato, que } \\
\text { dicen de Maquiz }\end{array}$ & L. J. Velázquez \\
\hline II $2 / 7,0060$ & $35[4]$ & $\begin{array}{l}\text { Andujar (Jaén), llevada de Los } \\
\text { Villares o Andujar el viejo }\end{array}$ & L. J. Velázquez \\
\hline II $2 / 7,0067$ & $41[3]$ & Arjona (Jaén) & Mss. de M. Jimena \\
\hline II $2 / 7,0068$ & $43[3]$ & Arjona (Jaén) & L. J. Velázquez \\
\hline II $2 / 7,0069$ & $28[4]$ & Arjona (Jaén) & $\begin{array}{l}\text { Mss. de M. Jimena y de J. Gruter (p. 226, 8), } \\
\text { éste de Goltzio. También recoge la lectura de } \\
\text { J. Metelo, y A. Occon (p. 3, 5) }\end{array}$ \\
\hline II $2 / 7,0070$ & $28[3]$ & Arjona (Jaén) & Mss. de M. Jimena \\
\hline II $2 / 7,0071$ & $29[4]$ & Arjona (Jaén) & Mss. de M. Jimena \\
\hline II $2 / 7,0073$ & $29[3]$ & Arjona (Jaén) & Mss. de M. Jimena \\
\hline
\end{tabular}




\begin{tabular}{|c|c|c|c|}
\hline CIL II & Folios & Procedencia & Fuente \\
\hline II $2 / 7,0074$ & $34[3]$ & Arjona (Jaén) & $\begin{array}{l}\text { L. J. Velázquez. En nota recoge que Harduino } \\
\text { en sus Notas sobre Plinio, asegura que esta } \\
\text { inscripción es moderna y fingida, hipótesis } \\
\text { que no comparte L. J. Velázquez }\end{array}$ \\
\hline II $2 / 7,0075$ & $39[3]$ & Arjona (Jaén) & Mss. de F. Rus Puerta \\
\hline II2/7, 0077 & $49[4]$ & Arjona (Jaén) & Mss. de M. Jimena \\
\hline II $2 / 7,0079$ & $52[1]$ & Arjona (Jaén) & Mss. de M. Jimena \\
\hline II $2 / 7,0094$ & $43[4]$ & Porcuna (Jaén) & Mss. de Nicolás Antonio \\
\hline II2/7, 0097 & $77[4]$ & Porcuna (Jaén) & Mss. de Nicolás Antonio \\
\hline II $2 / 7,0098$ & $70[3]$ & Porcuna (Jaén) & Mss. de Nicolás Antonio \\
\hline II $2 / 7,0111$ & $60[2]$ & Porcuna (Jaén) & Mss. de J. Fernández Franco \\
\hline II $2 / 7,0112$ & $60[2]$ & Porcuna (Jaén) & Mss. de J. Tamayo de Salazar \\
\hline II $2 / 7,0120$ & $73[1]$ & Porcuna (Jaén) & Mss. de J. Tamayo de Salazar \\
\hline II $2 / 7,0141$ & $29[4]$ & Montoro (Córdoba) & J. Vázquez \\
\hline II2/7, 0147 & $81[2]$ & Montoro (Córdoba) & $\begin{array}{l}\text { Mss. de E. B. de Alfaro, También en L. A. } \\
\text { Muratori, y éste de G. Cattaneo }\end{array}$ \\
\hline II $2 / 7,0159$ & $68[4]$ & Montoro (Córdoba) & T. A. de Gusseme, de quien la vio y copió \\
\hline II $2 / 7,0180$ & $52[4]$ & Morente (Bujalance, Córdoba) & $\begin{array}{l}\text { Mss. de E. B. de Alfaro, de L. A. Muratori y } \\
\text { éste de G. Cattaneo }\end{array}$ \\
\hline II2/7, 0183 & $61[4]$ & Bujalance (Córdoba) & Mss. de E. B. de Alfaro \\
\hline II $2 / 7,0201$ & $66[4]$ & Córdoba (Córdoba) & L. J. Velázquez \\
\hline II $2 / 7,0212$ & $55[1]$ & El Carpio (Córdoba) & Mss. de E. B. de Alfaro \\
\hline II $2 / 7,0212$ & $42[4]$ & El Carpio (Córdoba) & Mss. de E. B. de Alfaro \\
\hline II $2 / 7,0212$ & $43[1]$ & Córdoba (Córdoba) & Mss. de P. Valera \\
\hline II $2 / 7,0214$ & $75[4]$ & El Carpio (Córdoba) & Mss. de E. B. de Alfaro \\
\hline II $2 / 7,0215$ & $67[3]$ & Montoro (Córdoba) & $\begin{array}{l}\text { T. A. de Gusseme. Los mss. de E. B. de } \\
\text { Alfaro la ubican en Villafranca (Córdoba) } \\
\text { inmediata a Montoso }\end{array}$ \\
\hline II2/7, 0243 & $51[1]$ & Córdoba (Córdoba) & L. J. Velázquez \\
\hline II $2 / 7,0257$ & $37[4]$ & Córdoba (Córdoba) & Mss. de E. B. de Alfaro \\
\hline II2/7, 0260 & $38[1]$ & Córdoba (Córdoba) & L. J. Velázquez \\
\hline II $2 / 7,0261$ & $38[3]$ & Córdoba (Córdoba) & L. J. Velázquez \\
\hline II $2 / 7,0262$ & $38[3]$ & Córdoba (Córdoba) & L. J. Velázquez \\
\hline II2/7, 0263 & 39 [1] & Córdoba (Córdoba) & L. J. Velázquez \\
\hline II $2 / 7,0264$ & $38[4]$ & Córdoba (Córdoba) & L. J. Velázquez \\
\hline II $2 / 7,0265$ & $39[1]$ & Córdoba (Córdoba) & L. J. Velázquez \\
\hline II $2 / 7,0278$ & $47[4]$ & Córdoba (Córdoba) & L. J. Velázquez \\
\hline II $2 / 7,0283$ & $50[1]$ & Córdoba (Córdoba) & L. J. Velázquez \\
\hline II $2 / 7,0285$ & $53[1]$ & Córdoba (Córdoba) & $\begin{array}{r}\text { L. J. Velázquez } \\
\end{array}$ \\
\hline II $2 / 7,0287$ & $55[1]$ & $\begin{array}{c}\text { Córdoba (Córdoba), casa de P. } \\
\text { Villaceballos }\end{array}$ & $\begin{array}{l}\text { L. J. Velázquez. También de L. A. Muratori y } \\
\text { éste de G. Cattaneo. }\end{array}$ \\
\hline
\end{tabular}




\begin{tabular}{|c|c|c|c|}
\hline CIL II & Folios & Procedencia & Fuente \\
\hline II $2 / 7,0294$ & $48[3]$ & Córdoba (Córdoba) & Mss. de E. B. de Alfaro \\
\hline II $2 / 7,0300$ & $71[2]$ & Córdoba (Córdoba) & L. J. Velázquez \\
\hline II $2 / 7,0315$ & $53[1]$ & Córdoba (Córdoba) & L. J. Velázquez \\
\hline II $2 / 7,0332$ & $34[4]$ & Córdoba (Córdoba) & Mss. de E. B. de Alfaro \\
\hline II $2 / 7,0336$ & $61[2]$ & Córdoba (Córdoba) & L. J. Velázquez \\
\hline II $2 / 7,0338$ & $65[4]$ & Córdoba (Córdoba) & L. J. Velázquez \\
\hline II $2 / 7,0342$ & $70[1]$ & Córdoba (Córdoba) & Mss. de E. B. de Alfaro \\
\hline II $2 / 7,0347$ & $74[4]$ & Córdoba (Córdoba) & Mss. de E. B. de Alfaro \\
\hline II $2 / 7,0349$ & $82[1]$ & Córdoba (Córdoba) & Mss. de E. B. de Alfaro \\
\hline II $2 / 7,0382$ & $69[2]$ & Córdoba (Córdoba) & L. J. Velázquez \\
\hline II $2 / 7,0390$ & $67[1]$ & Córdoba (Córdoba) & L. J. Velázquez \\
\hline II $2 / 7,0395$ & $59[1]$ & Córdoba (Córdoba) & L. J. Velázquez. En nota II2/7, 433 \\
\hline II $2 / 7,0395$ & $74[3]$ & Córdoba (Córdoba) & $\begin{array}{l}\text { L. J. Velázquez. El original de esta inscrip- } \\
\text { ción estaba antiguamente a la espalda de otra } \\
\text { inscripción antigua que D. Pedro de Villa- } \\
\text { ceballos en cuya casa se conserva, la hizo } \\
\text { copiar de nuevo en un mármol la inscripción } \\
\text { de que aquí se trata y de la que copié yo }\end{array}$ \\
\hline II2/7, 0419 & $79[1]$ & Córdoba (Córdoba) & J. Vázquez, de quien la vio y copió \\
\hline II $2 / 7,0421$ & $58[1]$ & Córdoba (Córdoba) & L. J. Velázquez \\
\hline II $2 / 7,0426$ & $58[2]$ & Córdoba (Córdoba) & Vázquez, de quien la vio y la copió \\
\hline II $2 / 7,0434$ & $59[2]$ & Córdoba (Córdoba) & L. J. Velázquez \\
\hline II $2 / 7,0436$ & $59[3]$ & Córdoba (Córdoba) & L. J. Velázquez \\
\hline II2/7, 0444 & $60[1]$ & Córdoba (Córdoba) & L. J. Velázquez \\
\hline II $2 / 7,0445$ & $60[1]$ & Córdoba (Córdoba) & L. J. Velázquez \\
\hline II $2 / 7,0449$ & $60[4]$ & Córdoba (Córdoba) & L. J. Velázquez \\
\hline II $2 / 7,0452$ & $61[2]$ & Córdoba (Córdoba) & Mss. de E. B. de Alfaro \\
\hline II2/7, 0467 & $63[4]$ & Córdoba (Córdoba) & L. J. Velázquez \\
\hline II $2 / 7,0472$ & $65[1]$ & Córdoba (Córdoba) & L. J. Velázquez \\
\hline II $2 / 7,0473$ & $80[1]$ & Córdoba (Córdoba) & L. J. Velázquez \\
\hline II $2 / 7,0474$ & $65[2]$ & Córdoba (Córdoba) & L. J. Velázquez \\
\hline II $2 / 7,0478$ & $59[3]$ & Córdoba (Córdoba) & L. J. Velázquez \\
\hline II2/7, 0479 & $66[4]$ & Córdoba (Córdoba) & Mss. de E. B. de Alfaro \\
\hline II $2 / 7,0489$ & $67[4]$ & Córdoba (Córdoba) & L. J. Velázquez \\
\hline II $2 / 7,0490$ & $67[4]$ & Córdoba (Córdoba) & L. J. Velázquez \\
\hline II2/7, 0496 & $68[2]$ & Córdoba (Córdoba) & L. J. Velázquez \\
\hline II2/7, 0497 & $68[3]$ & Córdoba (Córdoba) & L. J. Velázquez \\
\hline II $2 / 7,0501$ & $\begin{array}{c}69 \text { [1]- } \\
69 \text { [2] }\end{array}$ & Córdoba (Córdoba) & L. J. Velázquez \\
\hline II $2 / 7,0506$ & $80[1]$ & Córdoba (Córdoba) & Mss. de E. B. de Alfaro \\
\hline II $2 / 7,0542$ & $73[1]$ & Córdoba (Córdoba) & J. Vázquez, de quien la vio y copió \\
\hline
\end{tabular}




\begin{tabular}{|c|c|c|c|}
\hline CIL II & Folios & Procedencia & Fuente \\
\hline II $2 / 7,0548$ & $73[4]$ & Córdoba (Córdoba) & L. J. Velázquez \\
\hline III/7, 0550 & $74[4]$ & Córdoba (Córdoba) & L. J. Velázquez \\
\hline III/7, 0553 & $74[3]$ & Córdoba (Córdoba) & L. J. Velázquez \\
\hline II $2 / 7,0562$ & $76[1]$ & Córdoba (Córdoba) & L. J. Velázquez \\
\hline II $2 / 7,0576$ & $43[3]$ & Córdoba (Córdoba) & L. J. Velázquez \\
\hline III/7, 0717 & 64 [2] & Córdoba (Córdoba) & L. J. Velázquez \\
\hline II $2 / 7,0723$ & $73[1]$ & Córdoba (Córdoba) & L. J. Velázquez \\
\hline III/7, 0727 & $71[1]$ & Córdoba (Córdoba) & Mss. de E. B. de Alfaro \\
\hline II2/7, 0739 & $71[1]$ & $\begin{array}{l}\text { En el contorno que dicen de las } \\
\text { Mezquitillas junto a las Posadas } \\
\text { (Córdoba) }\end{array}$ & A. M. Burriel, de quien la vio y copió \\
\hline II $2 / 7,0777$ & $43[1]$ & Villanueva de la Jara (Cuenca) & Mss. de P. Valera \\
\hline II $2 / 7,0886$ & $30[3]$ & Azuaga (Badajoz) & J. Vázquez \\
\hline II $2 / 7,0887$ & $32[3]$ & Azuaya (Badajoz) & J. Vázquez \\
\hline II2/7, 0903 & $33[1]$ & Zalamea de la Serena (Badajoz) & L. J. Velázquez \\
\hline II $2 / 7,0903$ & $103[2]$ & Zalamea de la Serena (Badajoz) & L. J. Velázquez \\
\hline II $2 / 7,0915$ & $68[3]$ & Zalamea de la Serena (Badajoz) & L. J. Velázquez \\
\hline II2/7, 0916 & $69[3]$ & Zalamea de la Serena (Badajoz) & L. J. Velázquez \\
\hline II2/7, 0917 & $\begin{array}{l}69[4]- \\
70[1]\end{array}$ & Zalamea de la Serena (Badajoz) & L. J. Velázquez \\
\hline II2/7, 0919 & $75[3]$ & Zalamea de la Serena (Badajoz) & L. J. Velázquez \\
\hline II $2 / 7,0958$ & $75[1]$ & $\begin{array}{c}\text { Ermita de Ntra. Sra. de la } \\
\text { Piedra Escrita, a media legua de } \\
\text { Campanario (Badajoz) }\end{array}$ & De quien la vio y copió \\
\hline II2/7, 0961 & $67[2]$ & $\begin{array}{l}\text { Ermita de Ntra. Sra. De la } \\
\text { Piedra Escrita, a media legua de } \\
\text { Campanario (Badajoz) }\end{array}$ & A. M. Burriel, de quien la vio y copió \\
\hline II $2 / 7,1004$ & $59[2]$ & Villagarcía de la Torre (Badajoz) & L. J. Velázquez \\
\hline II $2 / 7,2058$ & $37[4]$ & Córdoba (Córdoba) & J. Vázquez \\
\hline II $2 / 7,28-29$ & $45[1]$ & $\begin{array}{l}\text { Mengibar (Jaén) llevada de } \\
\text { Maquiz, ruinas inmediatas. }\end{array}$ & L. J. Velázquez \\
\hline Sin texto & $25[3]$ & Porcuna (Jaén) & Mss. de P. Valera \\
\hline Sin texto & $25[3]$ & $\begin{array}{l}\text { Paimogo, Campo de Andévalo } \\
\text { (Sevilla) }\end{array}$ & Mss. de P. Valera \\
\hline Sin texto & $25[3]$ & Granada & L. J. Velázquez \\
\hline Sin texto & $25[3]$ & Granada & L. J. Velázquez \\
\hline Sin texto & $25[3]$ & Granada & L. J. Velázquez \\
\hline Sin texto & $25[4]$ & Granada & L. J. Velázquez \\
\hline Sin texto & $25[4]$ & Granada & L. J. Velázquez \\
\hline Sin texto & $25[4]$ & Granada & De quien lo vio, y copió \\
\hline Sin texto & $25[4]$ & Granada & L. J. Velázquez \\
\hline Sin texto & $26[1]$ & Granada & L. J. Velázquez \\
\hline
\end{tabular}




\begin{tabular}{|c|c|c|c|}
\hline CIL II & Folios & Procedencia & Fuente \\
\hline Sin texto & $33[3]$ & Alcántara (Cáceres) & L. J. Velázquez \\
\hline Sin texto & $36[4]$ & Granada (Granada) & L. J. Velázquez \\
\hline Sin texto & $40[1]$ & Granada (Granada) & L. J. Velázquez \\
\hline Sin texto & $40[1]$ & Cartagena (Murcia) & J. Talamanco \\
\hline Sin texto & $40[1]$ & Mérida (Badajoz) & L. J. Velázquez \\
\hline Sin texto & $44[1]$ & Granada (Granada) & L. J. Velázquez \\
\hline Sin texto & $45[2]$ & Prohendos (Lugo) & De un antiguo ms. anónimo \\
\hline Sin texto & $45[4]$ & Zamora (Zamora) & Pastor. \\
\hline Sin texto & $56[4]$ & Salvatierra (Cáceres) & Sin fuente \\
\hline Sin texto & $58[3]$ & Tortosa (Tarragona) & F. Pérez Bayer \\
\hline Sin texto & $80[4]$ & $\begin{array}{c}\text { Junto a Castro del Río y Espejo } \\
\text { (Córdoba) }\end{array}$ & Mss. de E. B. de Alfaro \\
\hline Sin texto & $81[2]$ & Mérida (Badajoz) & L. J. Velázquez \\
\hline Sin texto ${ }^{\mathrm{iii}}$ & $25[2]$ & $\begin{array}{c}\text { En la Ermita de Ntra. Sra. } \\
\text { del Cid, cerca de la Iglesuela } \\
\text { (Teruel) }\end{array}$ & $\begin{array}{l}\text { Mss. de P. Valera, Varias inscripciones recogi- } \\
\text { das por Pedro Valera enel año } 1589 \text { de Jesús, } \\
\text { que vio caminando con su amo el Duque (ms. } \\
\text { encuadernado en páginas en } 4^{\circ} \text {, que le comu- } \\
\text { nica a Valdeflores J. de Cevallos). También } \\
\text { queda recogida esta inscripción en el Ensayo } \\
\text { sobre los alfabetos delas letras desconocidas, } \\
\text { p. } 127 \text {, tomada del ms. de V.J. de Lastanosa }\end{array}$ \\
\hline Tachada & $48[1]$ & Mérida (Badajoz) & $\begin{array}{l}\text { L. J. Velázquez } \\
\end{array}$ \\
\hline Tachada & $48[2]$ & Cartagena (Murcia) & A. M. Burriel \\
\hline Tachada & $52[3]$ & Madrid (Madrid) & L. J. Velázquez \\
\hline Tachada & $55[2]$ & Valera de Arriba (Cuenca) & A. M. Burriel \\
\hline \multirow[t]{7}{*}{ Tachada } & $62[4]$ & Cabra (Córdoba) & Mss. de J. Fernández Franco \\
\hline & $29[2]$ & Granada & De quien lo vio, y copió, nota 38. \\
\hline & $30[2]$ & Santaella (Córdoba) & Mss. de Jerónimo. de Morales \\
\hline & $37[1]$ & Espejo (Córdoba) & Mss. de J. Fernández Franco \\
\hline & $50[1]$ & Denia (Alicante) & Mss. de P. Valera \\
\hline & $57[2]$ & Utrera (Sevilla) & Mss. de R. Caro \\
\hline & $60[3]$ & Fuentes (Sevilla) & P. Villaceballos \\
\hline
\end{tabular}

i. M. Almagro-Gorbea, Epigrafia prerromana: catálogo del Gabinete de Antigüedades, Madrid 2003.

ii. Flores de Oddouz, J., Monumentos descubiertos en la Antigua Illiberia, Illipula, o Granata, en Virtud de las Reales Ordenes de S.M.C, (B.N., R/39420).

iii. Estas inscripciones carecen de texto, aún así las hemos incluido para no romper el orden que sigue el corpus. 
APÉNDICE II

\begin{tabular}{|c|c|c|c|}
\hline $\mathrm{IHC}$ & Pliego & Procedencia & Fuente \\
\hline $0019 *$ & $45[2]$ & Sanlúcar la Mayor (Sevilla) & $\begin{array}{l}\text { Mss. de R. Caro } \\
\end{array}$ \\
\hline 0023 a & $106[2]$ & Mérida (Badajoz) & $\begin{array}{l}\text { Sacado de un ms. gótico de la Biblioteca de la } \\
\text { Catedral de Toledo (Códice de Azagra) }\end{array}$ \\
\hline 0033 & $105[3]$ & Mérida (Badajoz) & $\begin{array}{l}\text { L. J. Velázquez. } \\
\end{array}$ \\
\hline 0043 & $105[3]$ & $\begin{array}{l}\text { En la ermita de Nuestra Señora de } \\
\text { la Antigua }\end{array}$ & Mss. de Tamayo de Salazar \\
\hline 0045 & $105[2]$ & Hinojales (Sevilla) & Mss. de R. Caro \\
\hline 0055 & $106[2]-106[4]$ & Usagre (Badajoz) & L. J. Velázquez \\
\hline 0059 & $106[3]$ & Alcolea (Sevilla) & T. A. Guseme \\
\hline 0065 & $106[1]$ & Sevilla (Sevilla) & L. J. Velázquez \\
\hline 0071 & $105[2]$ & Salteras (Sevilla) & Mss. de R. Caro \\
\hline 0072 & $105[2]$ & Salteras (Sevilla) & Mss. de R. Caro \\
\hline 0073 & $106[4]$ & Salteras (Sevilla) & Mss. de R. Caro \\
\hline 0076 & $105[3]$ & $\begin{array}{l}\text { Sevilla, llevada de Alcalá de } \\
\text { Gudaira (Sevilla) }\end{array}$ & L. J. Velázquez. \\
\hline 0077 & $105[2]$ & Sanlúcar la Mayor (Sevilla) & Mss. de R. Caro \\
\hline 0078 & $105[1]$ & Sanlúcar la Mayor (Sevilla) & Mss. de R. Caro \\
\hline 0079 & $106[4]$ & Junto a Utrera (Sevilla) & Mss. de R. Caro \\
\hline 0085 & $105[4]$ & Medina Sidonia (Málaga) & L. J. Velázquez \\
\hline 0086 & $106[2]$ & Medina Sidonia (Málaga) & L. J. Velázquez. \\
\hline 0100 & $106[1]$ & Cabra (Córdoba) & $\begin{array}{l}\text { J. Vázquez. También en A. de Morales con otra } \\
\text { lectura diferente }\end{array}$ \\
\hline 0111 & $106[1]$ & $\begin{array}{l}\text { En la ermita de San Ambrosio, a } \\
\text { tres cuarto de legua de Bejel de } \\
\text { la Miel }\end{array}$ & L. J. Velázquez \\
\hline 0115 & $105[4]$ & Granada (Granada) & $\begin{array}{l}\text { L. J. Velázquez. También en F. Bermúdez de } \\
\text { Pedraza, Historia de Granada }\end{array}$ \\
\hline 0117 & $106[1]-106[2]$ & $\begin{array}{c}\text { Andujar (Jaén), llevada de la villa } \\
\text { de Arjona }\end{array}$ & L. J. Velázquez \\
\hline 0120 & $106[1]$ & Montoro (Córdoba) & T. A. Guseme \\
\hline 0127 & $82[1]-82[2]$ & Córdoba (Córdoba) & Mss. de E. B. de Alfaro \\
\hline 0128 & $106[2]$ & Córdoba (Córdoba) & L. J. Velázquez \\
\hline 0130 & $106[3]$ & Córdoba (Córdoba) & Mss. de E. B. de Alfaro \\
\hline 0155 & $105[3]$ & Toledo (Toledo) & L. J. Velázquez \\
\hline 0172 & $105[4]$ & Bailén (Jaén) & L. J. Velázquez \\
\hline 0176 & $105[4]$ & Cartagena (Murcia) & A. M. Burriel \\
\hline 0205 & $\begin{array}{c}106[4]-107 \\
{[1]}\end{array}$ & Ardales (Málaga) & M. Trabuco \\
\hline 0225 & $106[2]$ & Córdoba (Córdoba) & L. J. Velázquez \\
\hline Sin texto & $105[1]$ & Talavera de la Reina (Toledo) & L. J. Velázquez \\
\hline
\end{tabular}




\begin{tabular}{|c|c|c|c|}
\hline $\mathrm{IHC}$ & Pliego & Procedencia & Fuente \\
\hline Sin texto & $105[1]$ & Mérida (Badajoz) & L. J. Velázquez \\
\hline Sin texto & $106[2]$ & Mérida (Badajoz) & L. J. Velázquez \\
\hline Sin texto & $106[2]$ & Martos (Jaén) & L. J. Velázquez \\
\hline Sin texto & $106[4]$ & Lugar incierto cerca de Zaragoza & $\begin{array}{c}\text { J. F. A. de Uztarroz, Zaragoza antigua } \\
\text { manuscrita }\end{array}$ \\
\hline Sin texto & $106[4]$ & Espartiñas (Sevilla) & Mss. de P. Quirós \\
\hline
\end{tabular}

